Supplement of Atmos. Chem. Phys. Discuss., 15, 9815-9895, 2015

http://www.atmos-chem-phys-discuss.net/15/9815/2015/

doi:10.5194/acpd-15-9815-2015-supplement

(C) Author(s) 2015. CC Attribution 3.0 License.

(c) (i)

\title{
Development and optimization of a wildfire plume rise model based on remote sensing data inputs - Part 2
}

R. Paugam et al.

Correspondence to: R. Paugam (ronan.paugam@kcl.ac.uk) 


\section{Optimization of the PRMv2 model using the Markov chain Monte Carlo algorithm:}
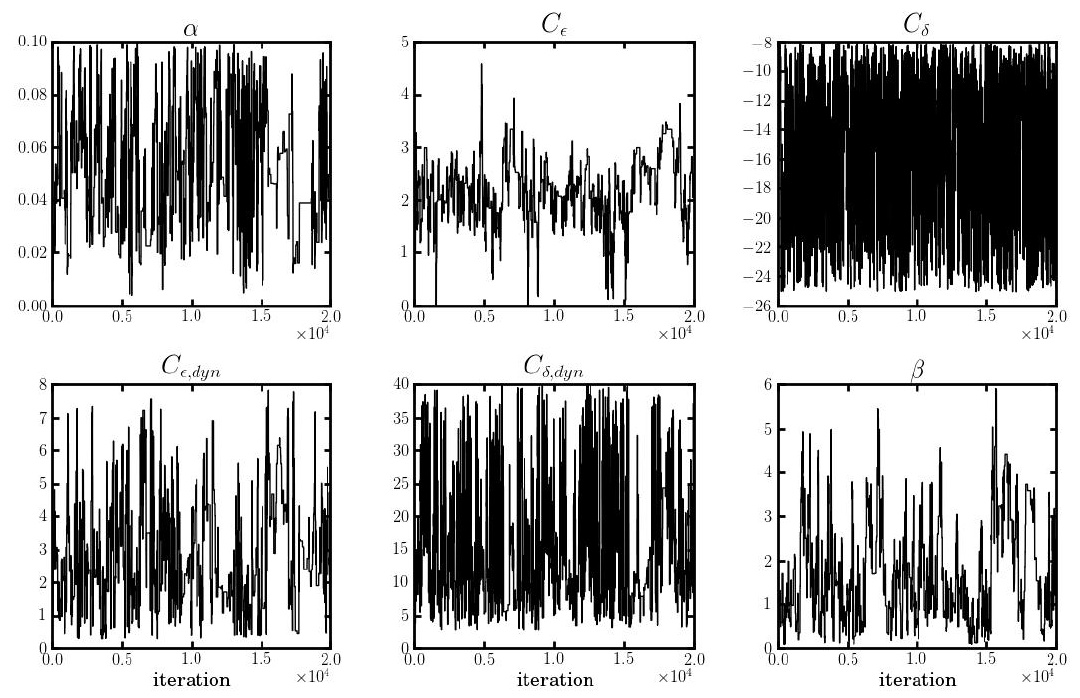

Figure S1: McMC parameters chain. 


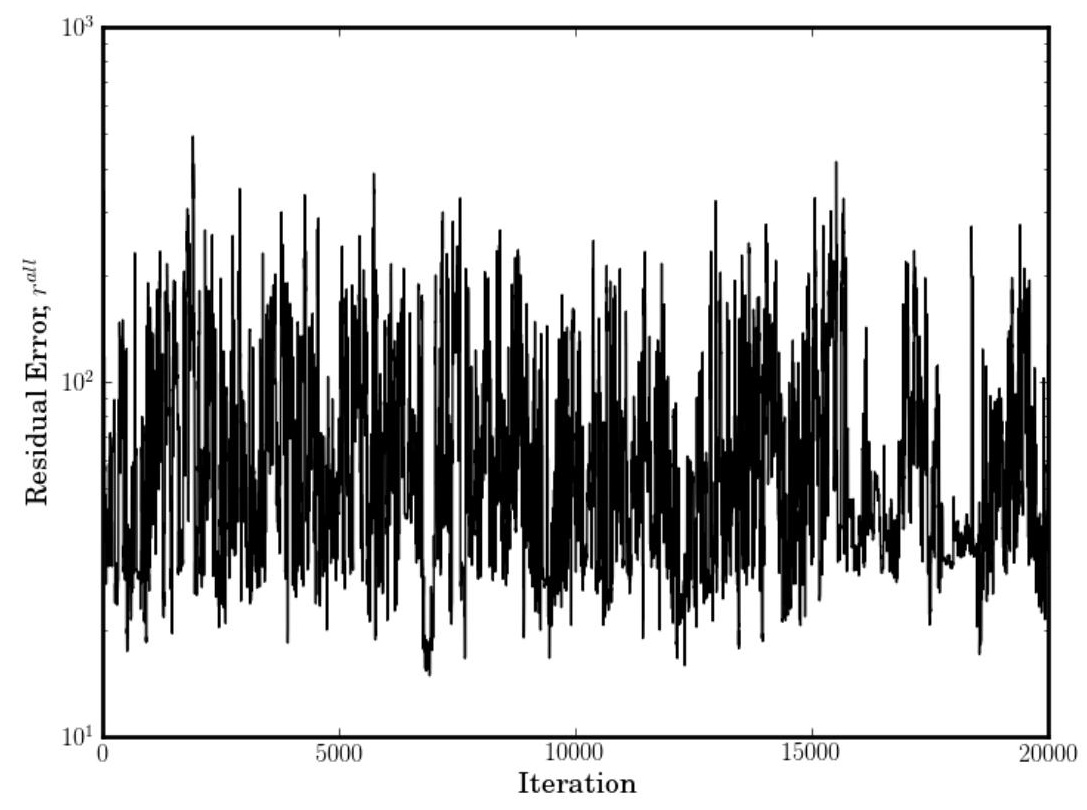

Figure S2: McMC residual error $r^{\text {all }}$ chain.

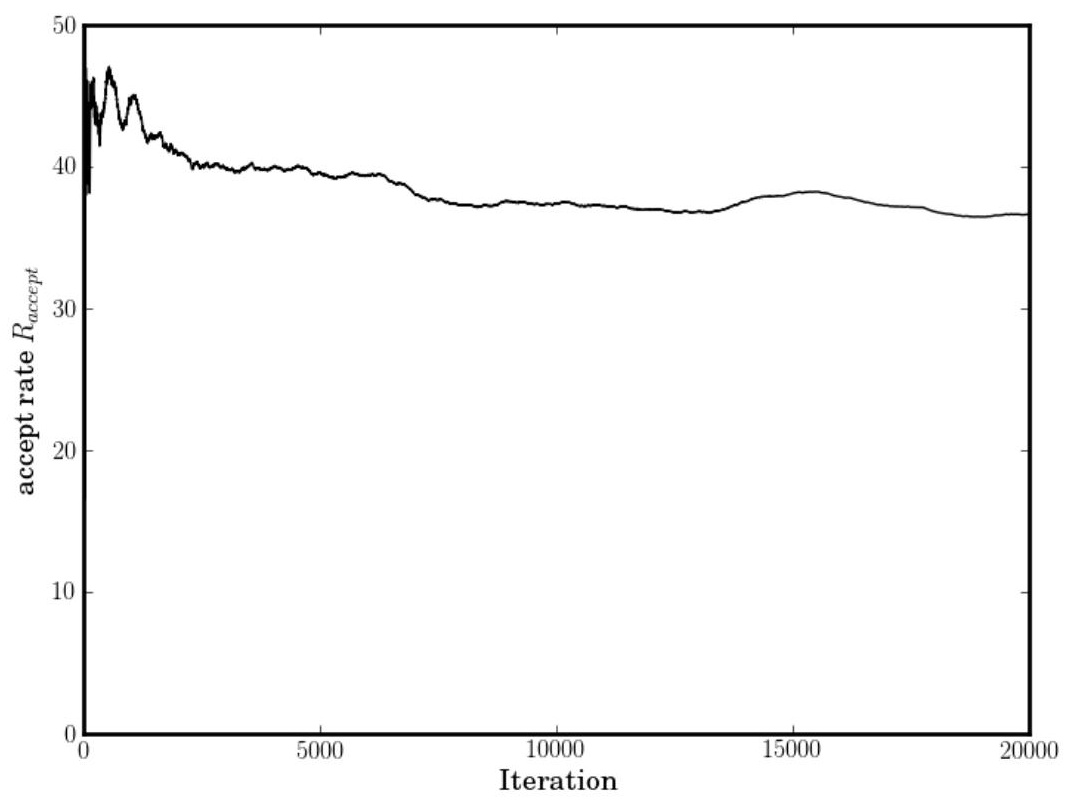

Figure S3: McMC acceptance Rate $R_{\text {accept }}$ chain. 


\section{Spatial distribution of InjH for Summer 2003 over North America modelled with PRMv0, PRMv1, and the Sofiev parameterization}

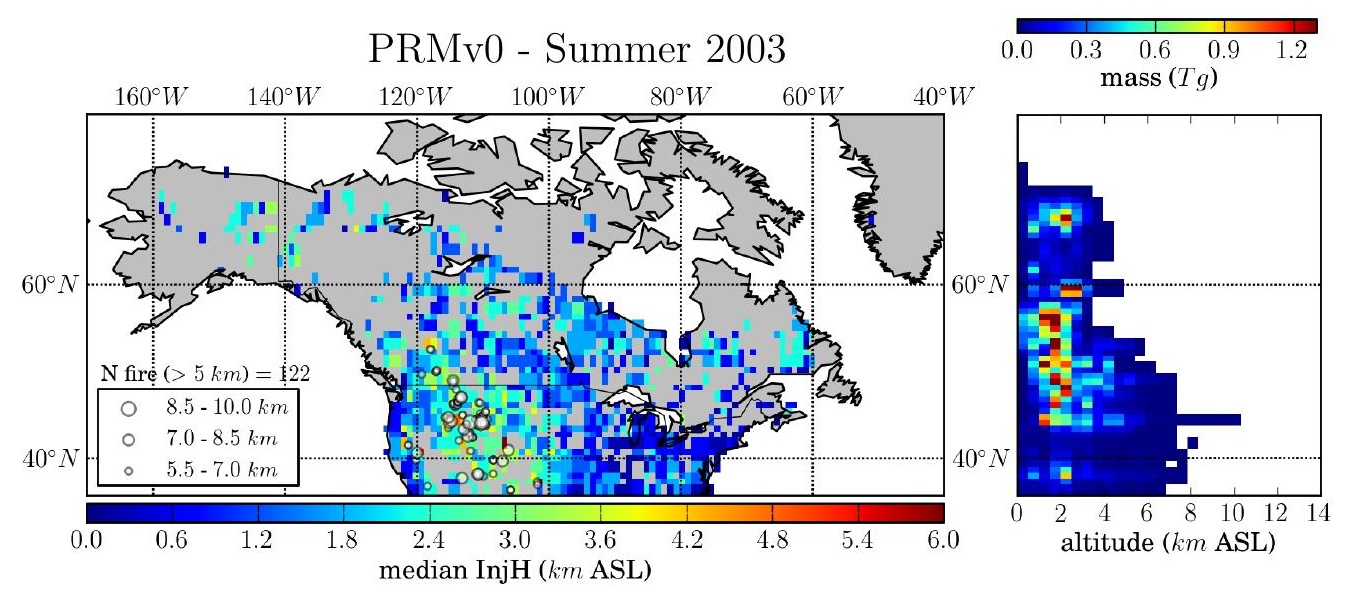

Figure S4: Seasonal maps of InjH distribution over North America for the year 2003. Fires occurrence is based on the collection 5 of the Moderate-resolution Imaging Spectroradiometer (MODIS) active fire product, and a simple model of $6 h$ persistence is used to model fire evolution. InjH is modelled with the PRMv0 model and gridded on a $1.0^{\circ}$ resolution map with a $500 \mathrm{~m}$ vertical grid resolution. For each season, horizontal distribution of the seasonal integrated InjH median (left plot), single fire events with a modelled plume above $5 \mathrm{~km}$ (left plot), and vertical burnt mass distribution integrated over the longitude (right plot) are shown. 


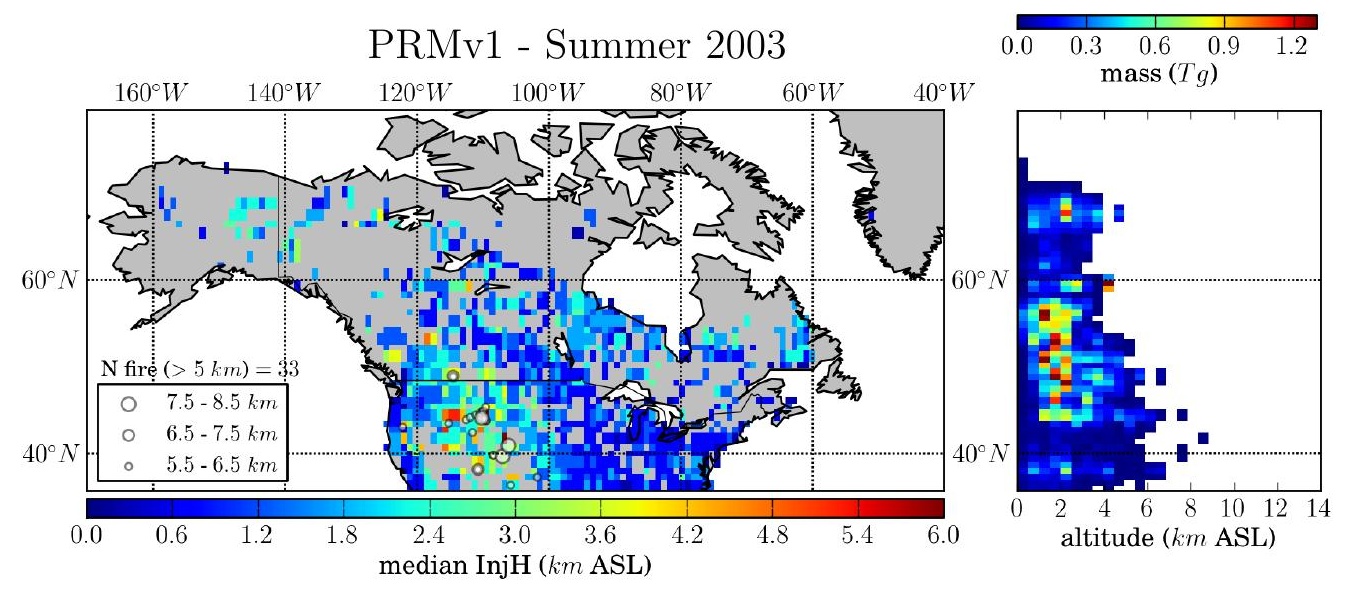

Figure S5: same as for Figure S4, but using the model PRMv1.

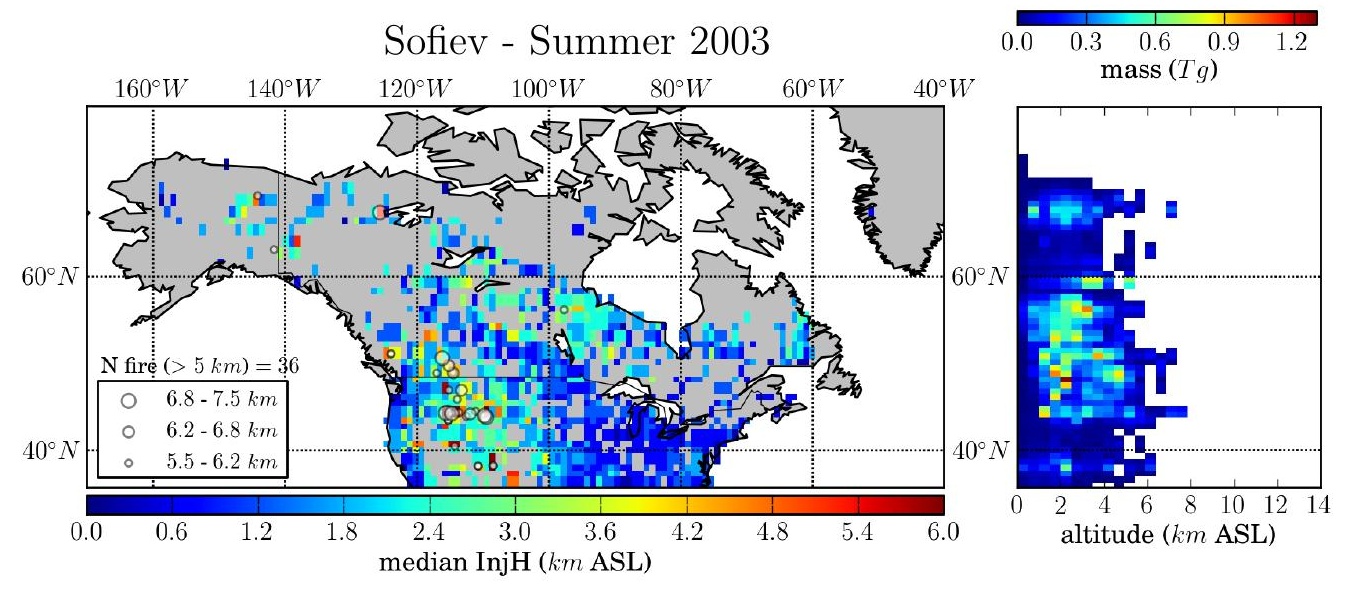

Figure S6: same as for Figure S4, but using the sofiev parameterization. 
3 Time evolution of the 38 "good" fire dataset defined in Section 4.2 


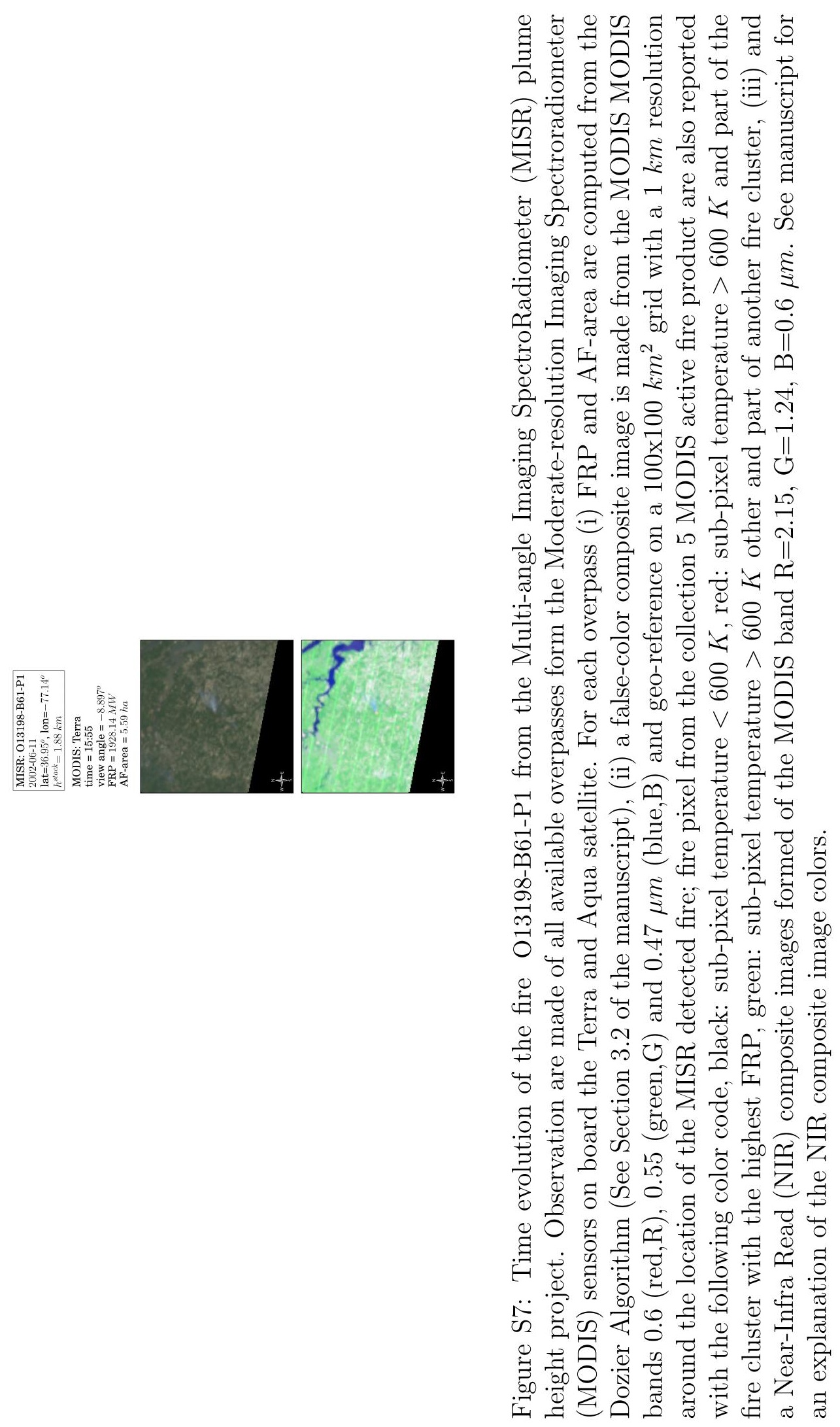




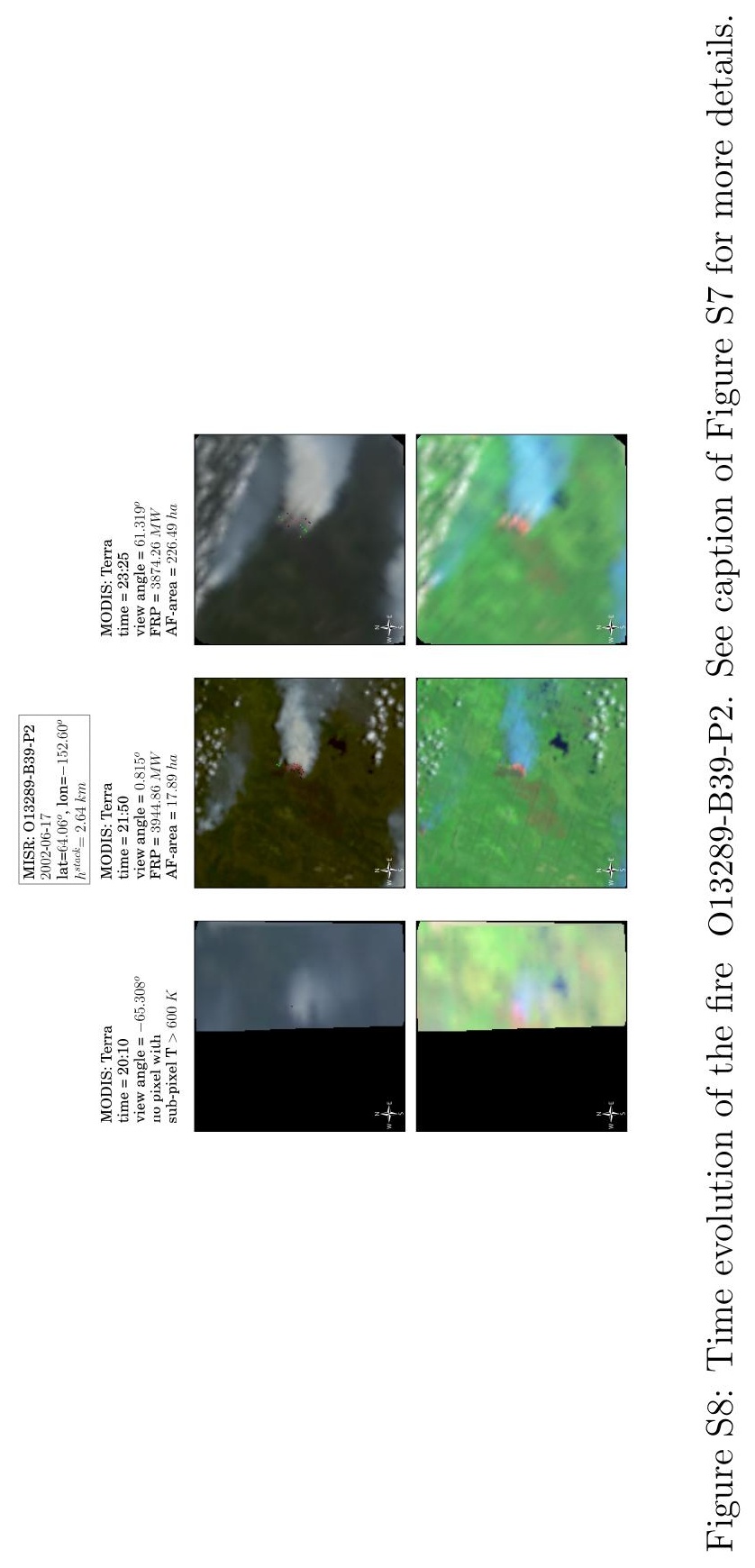




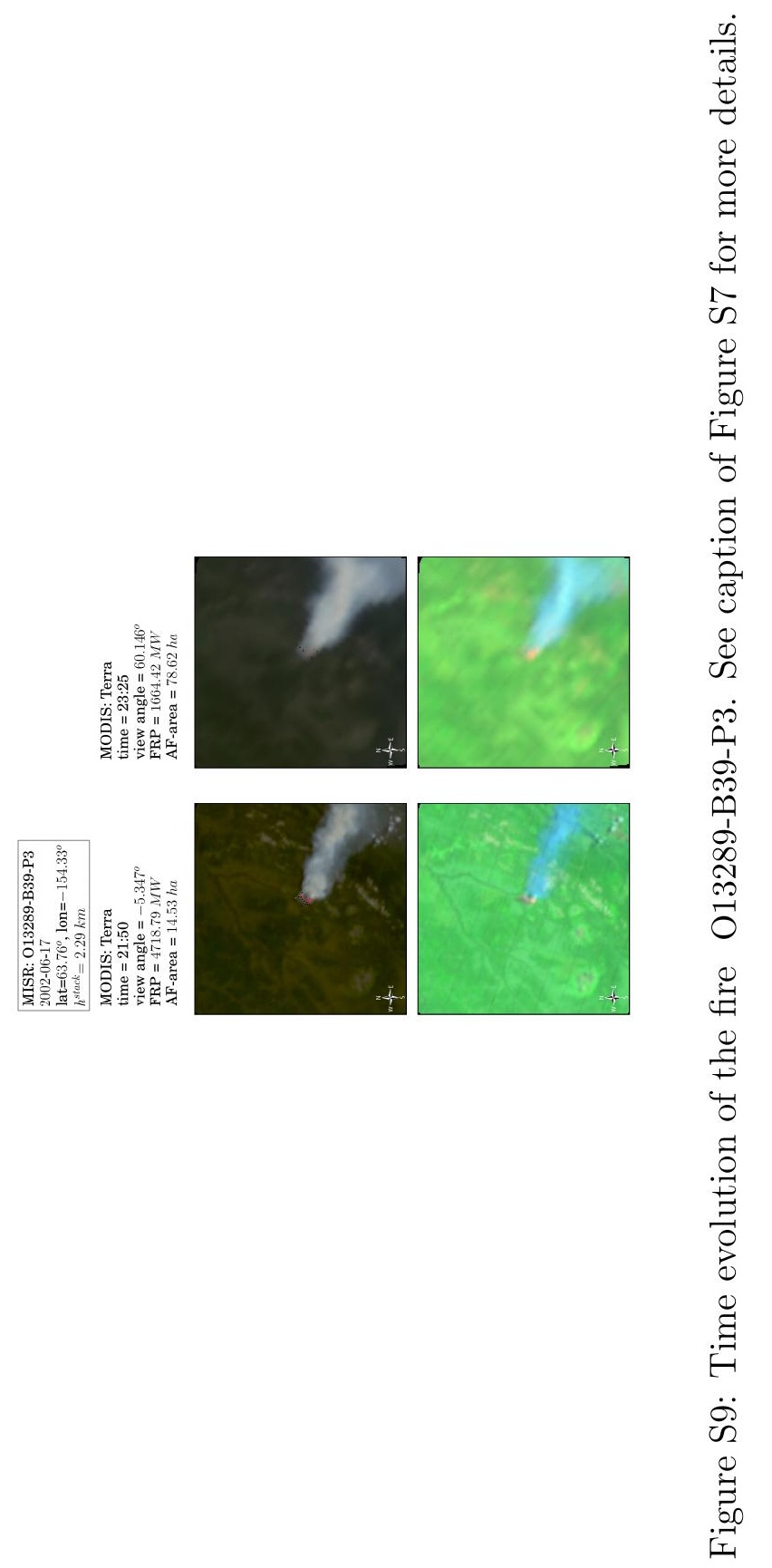




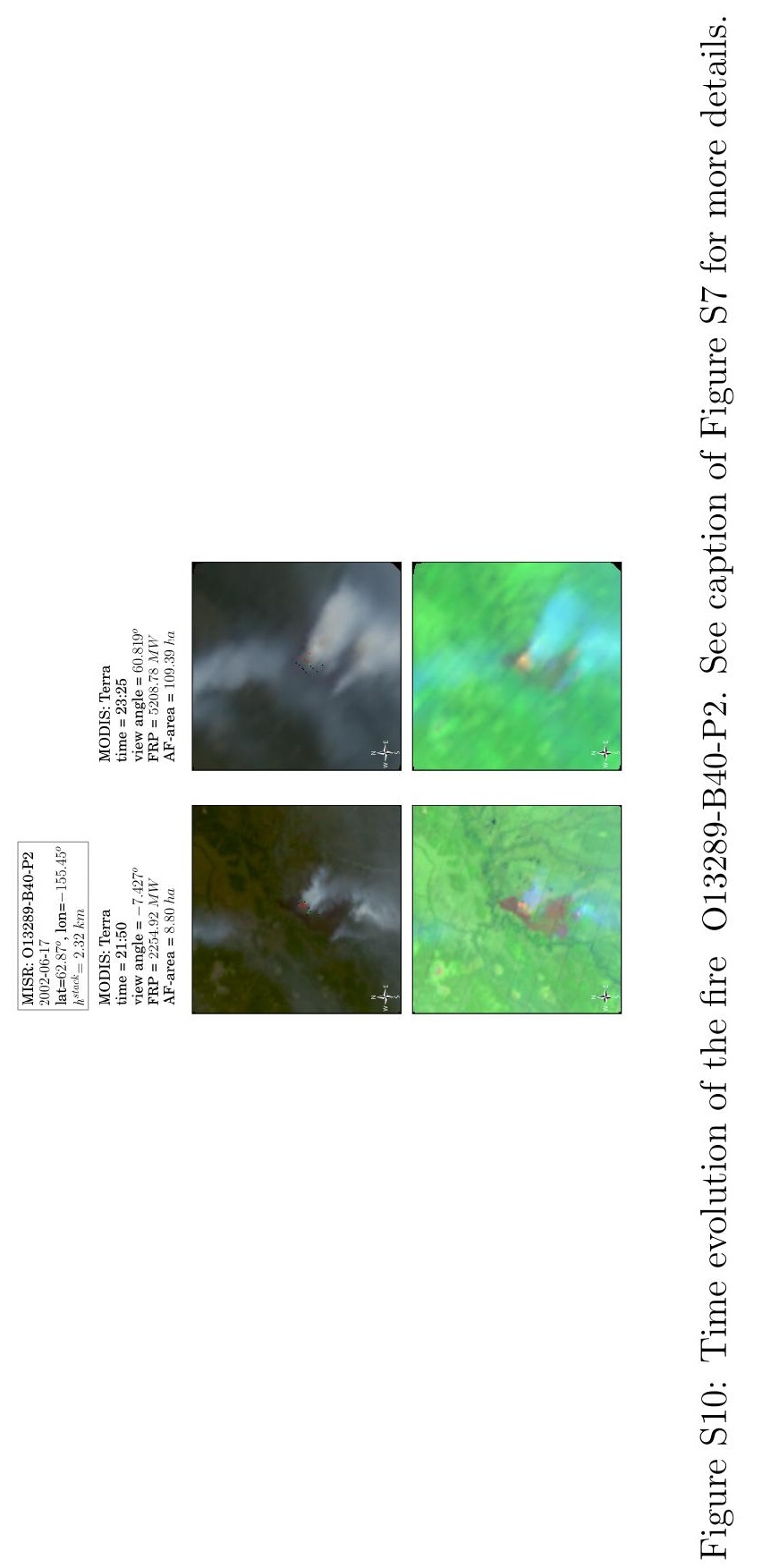




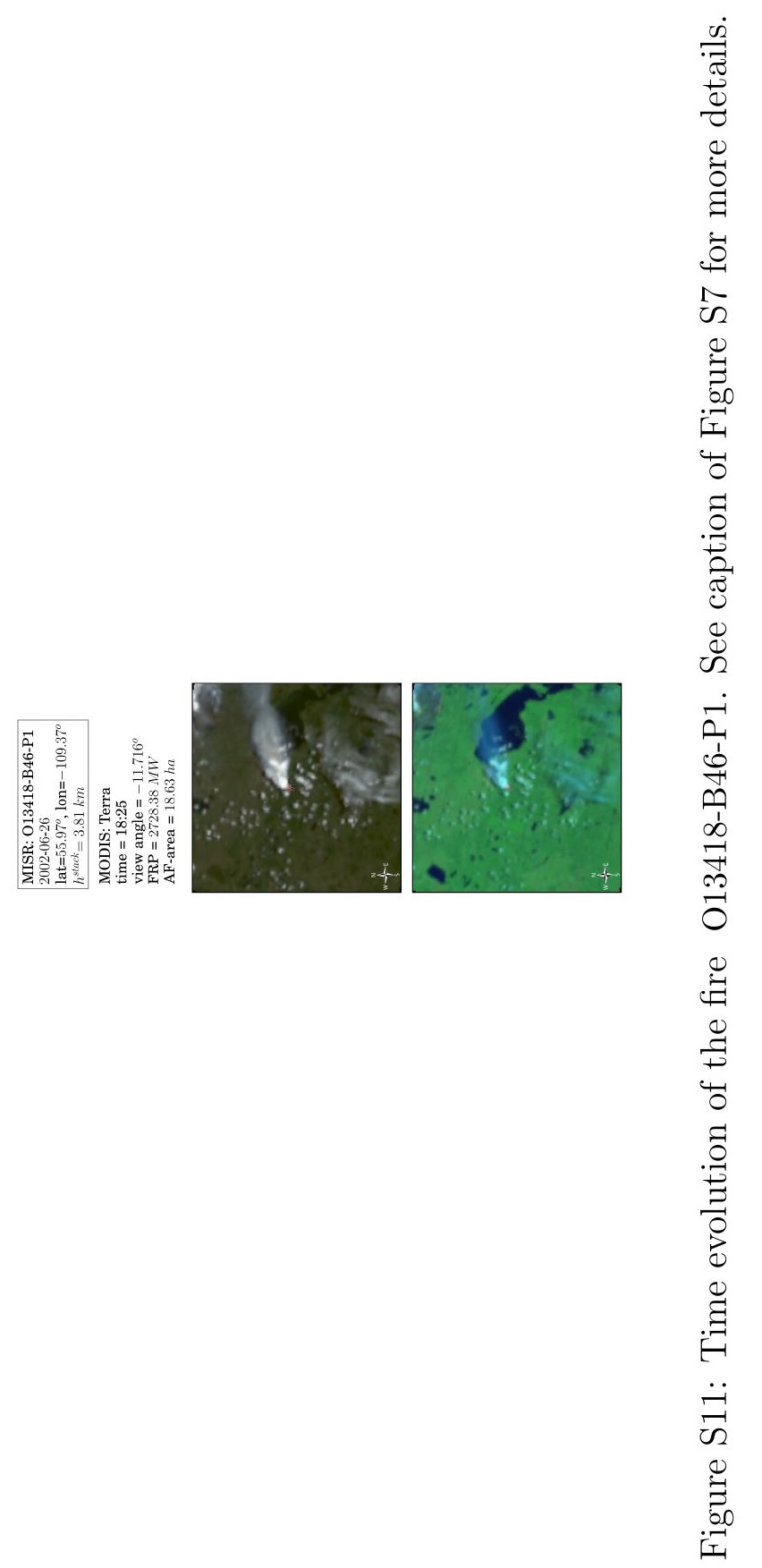




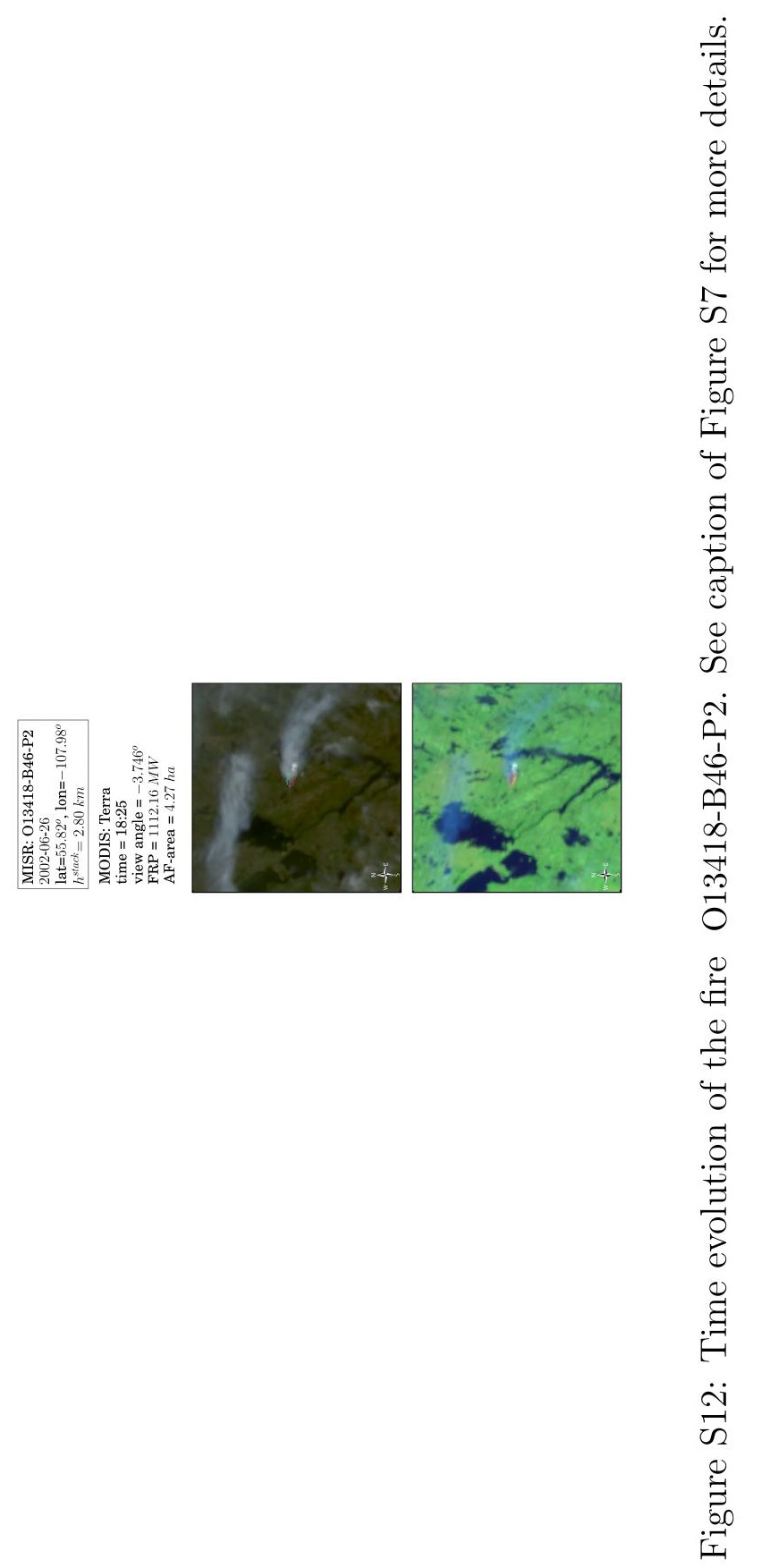




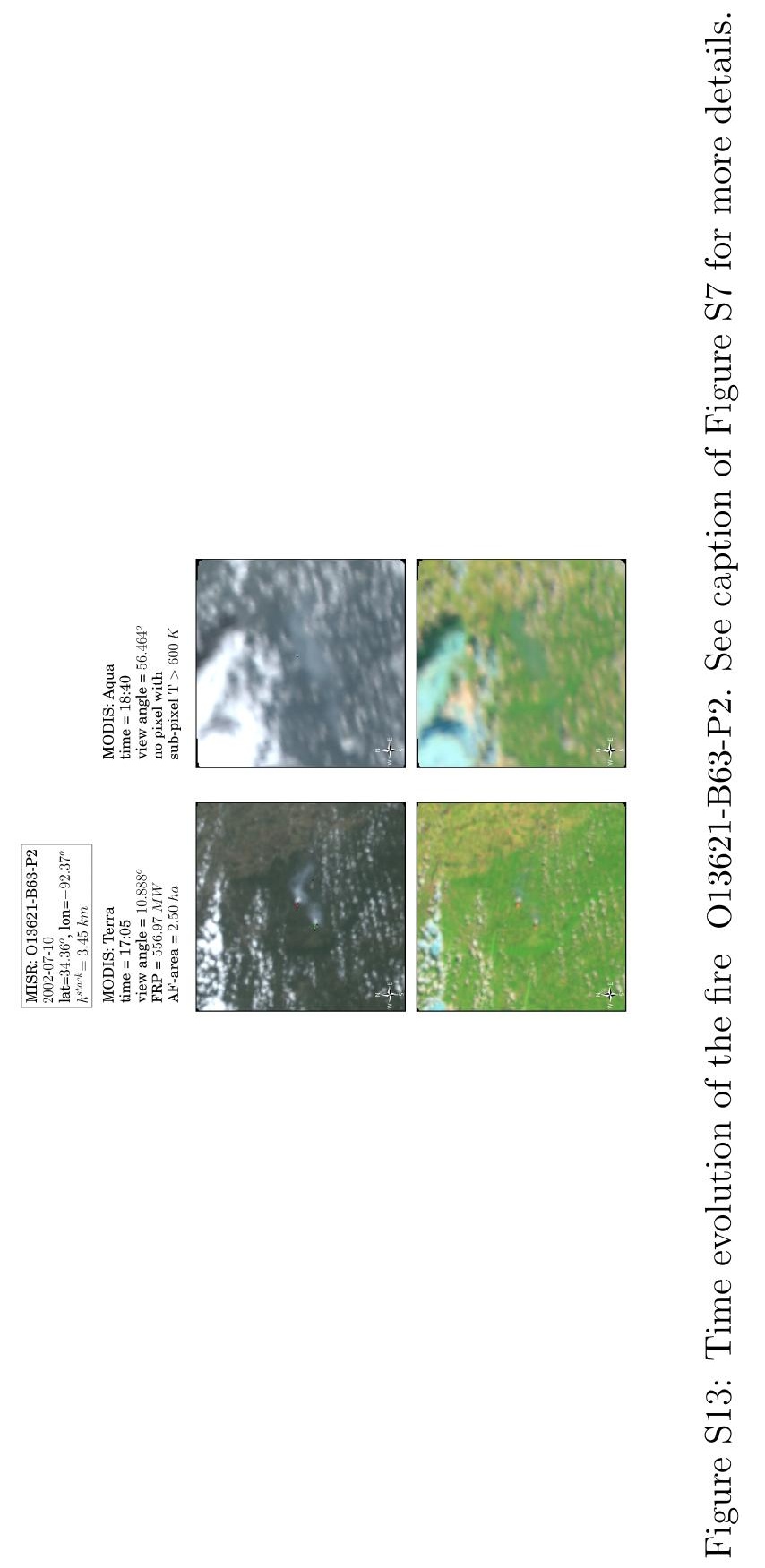




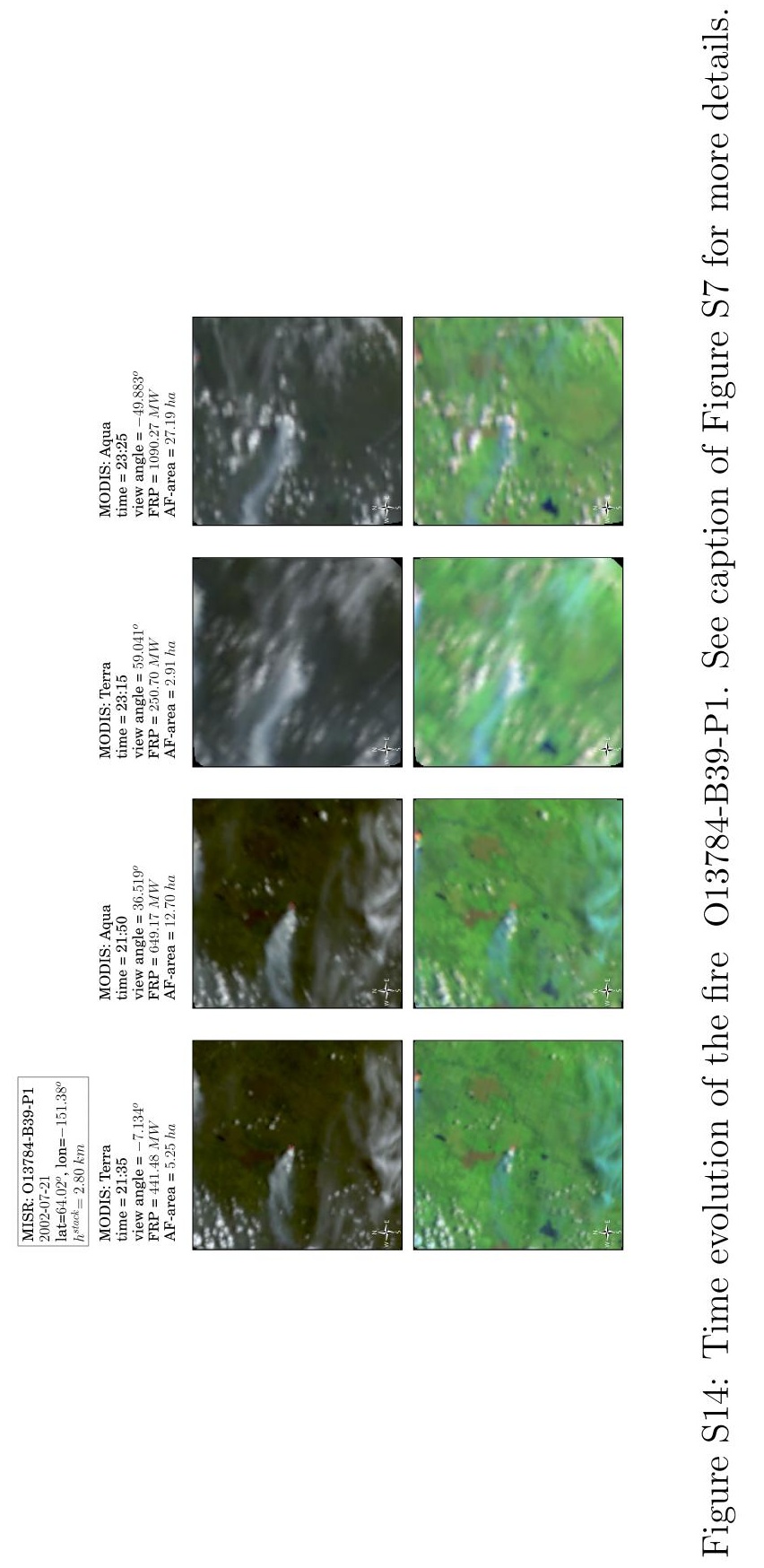




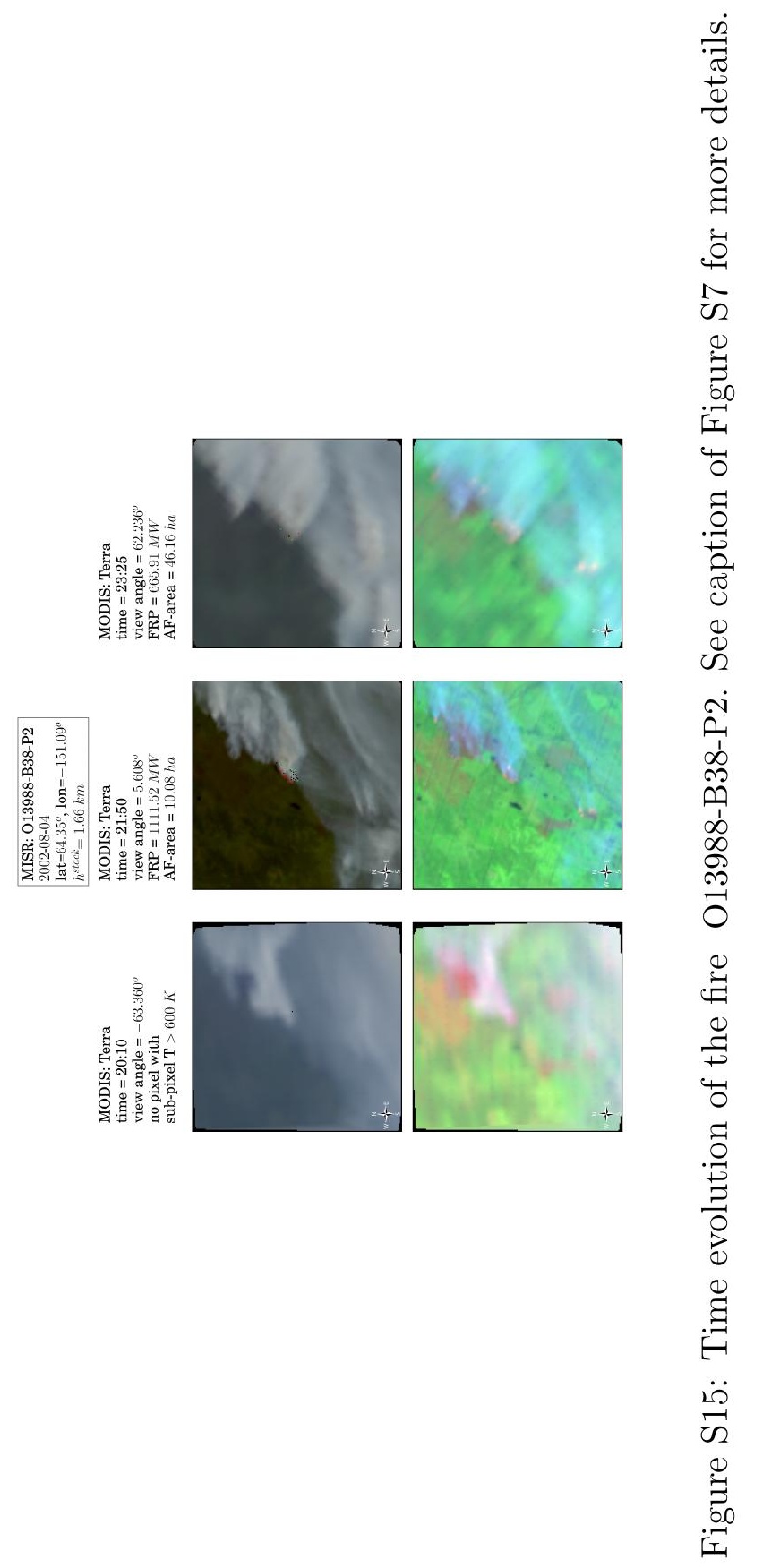




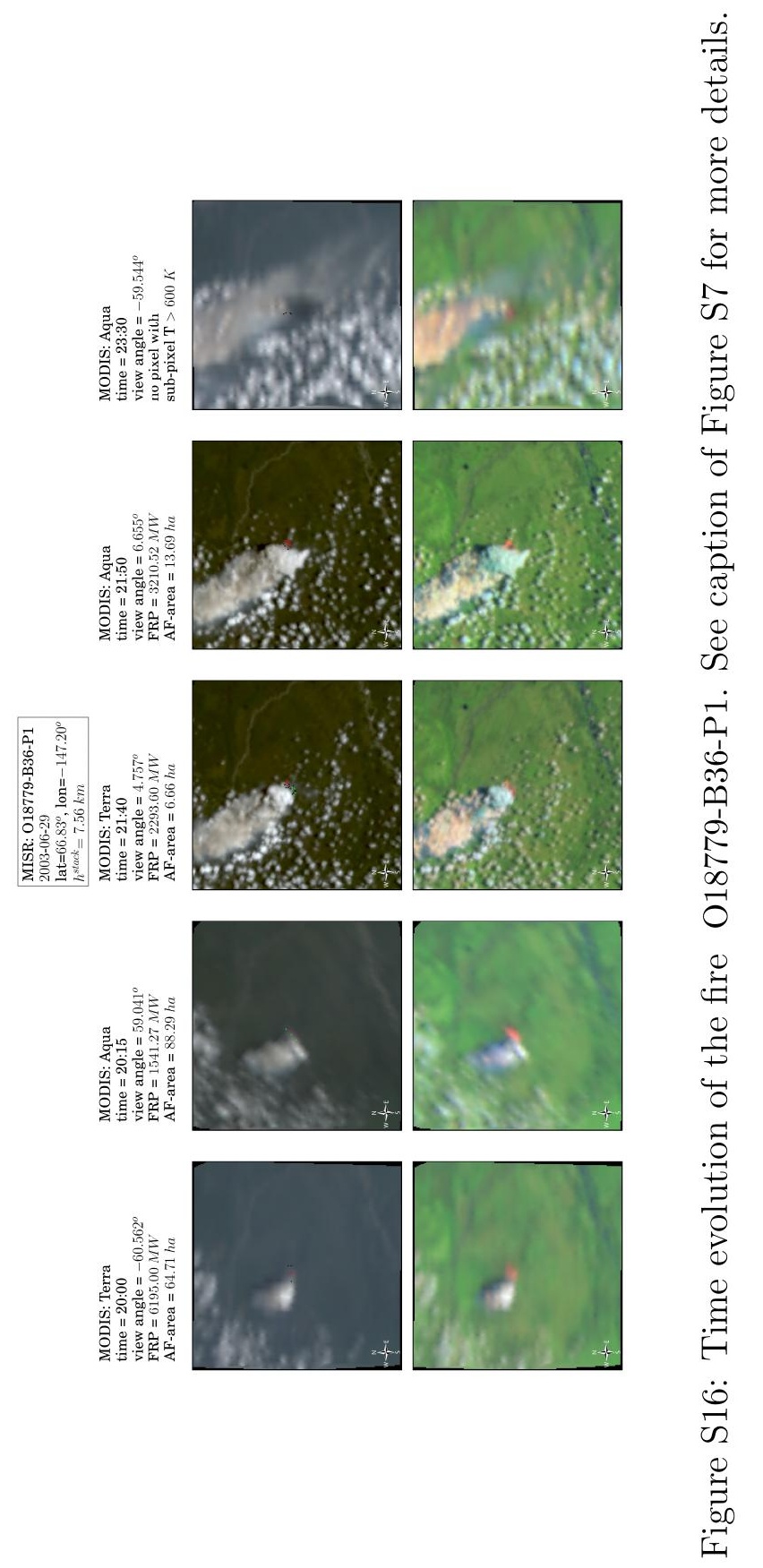




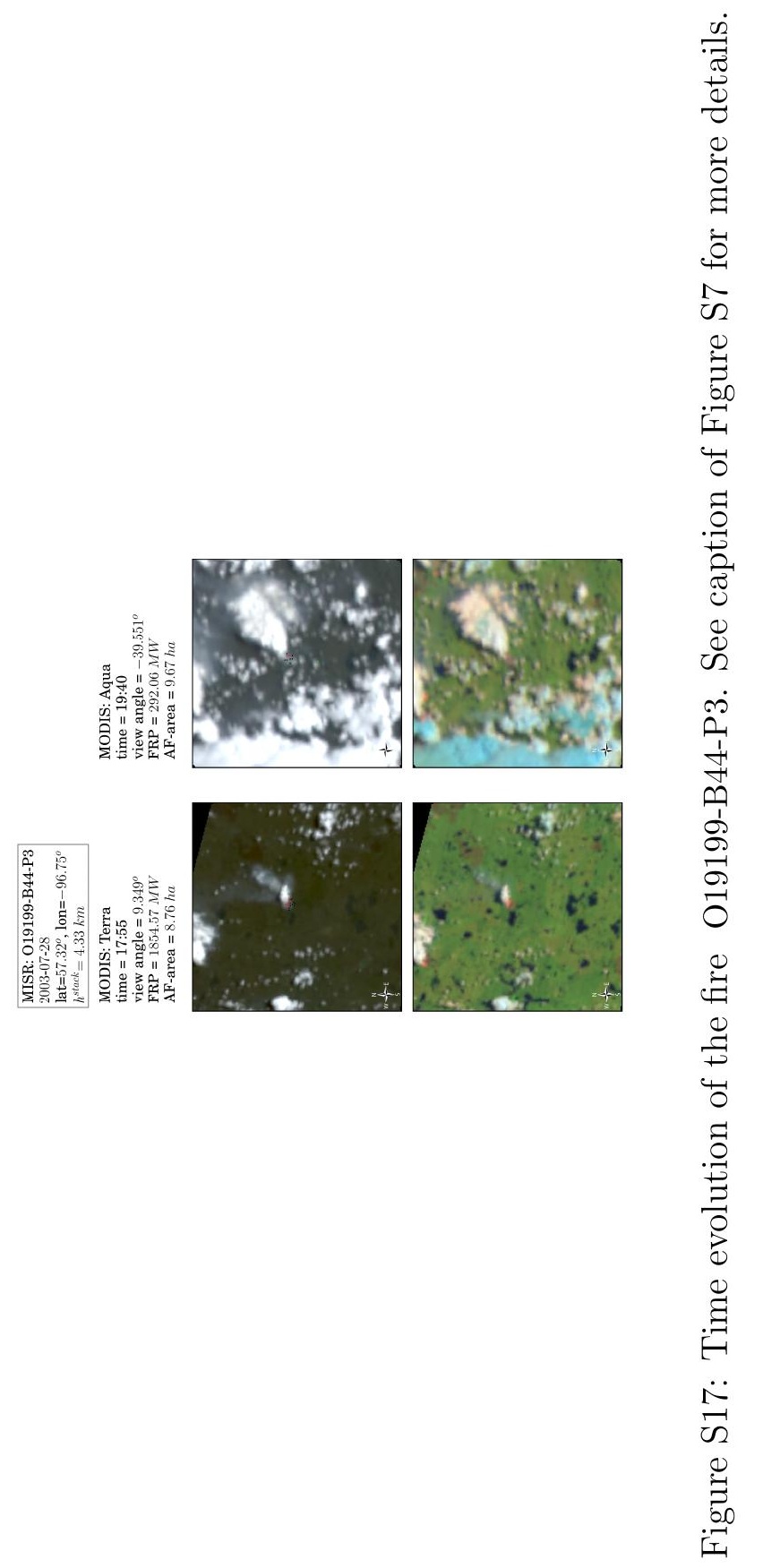




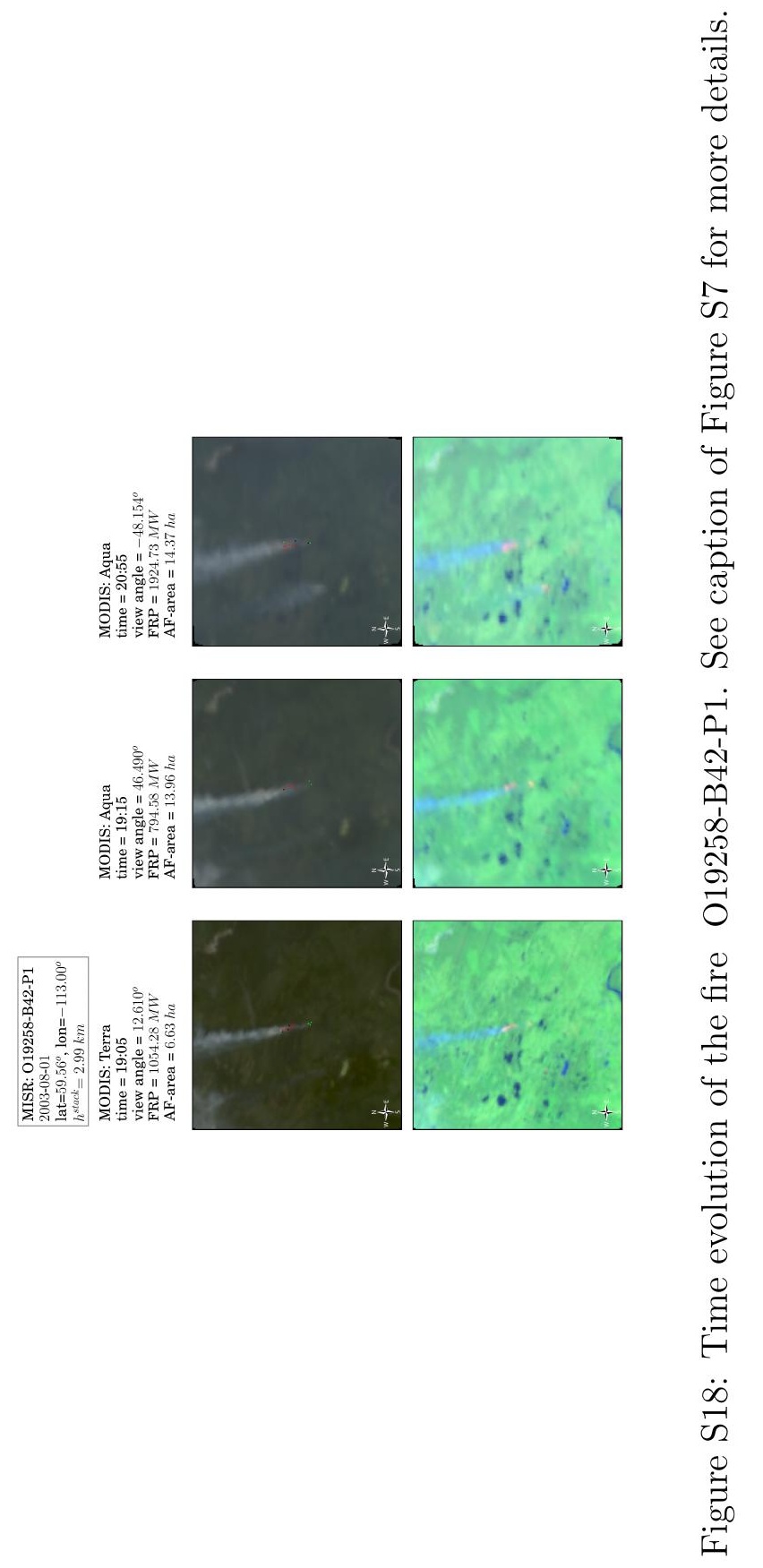




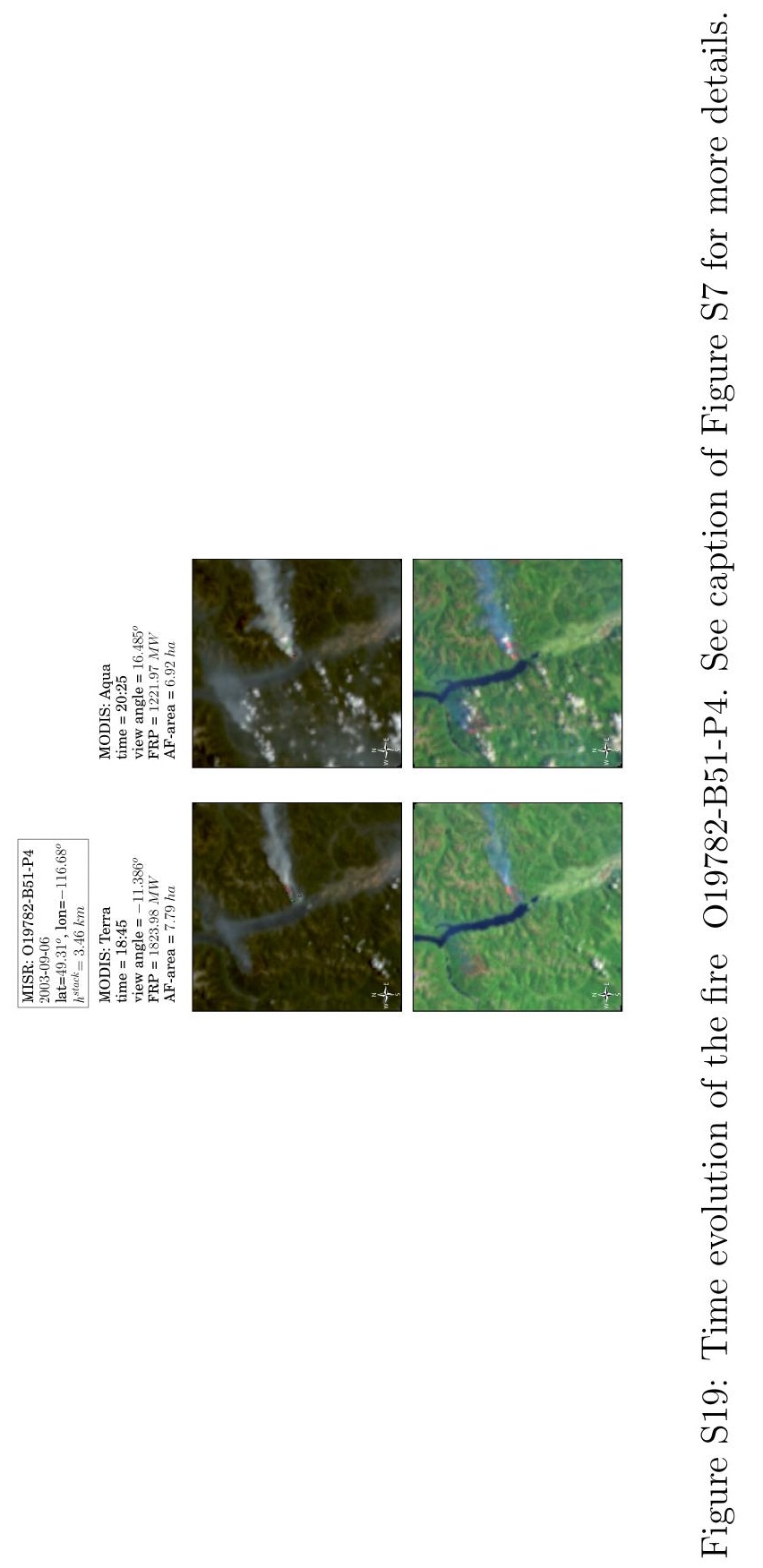




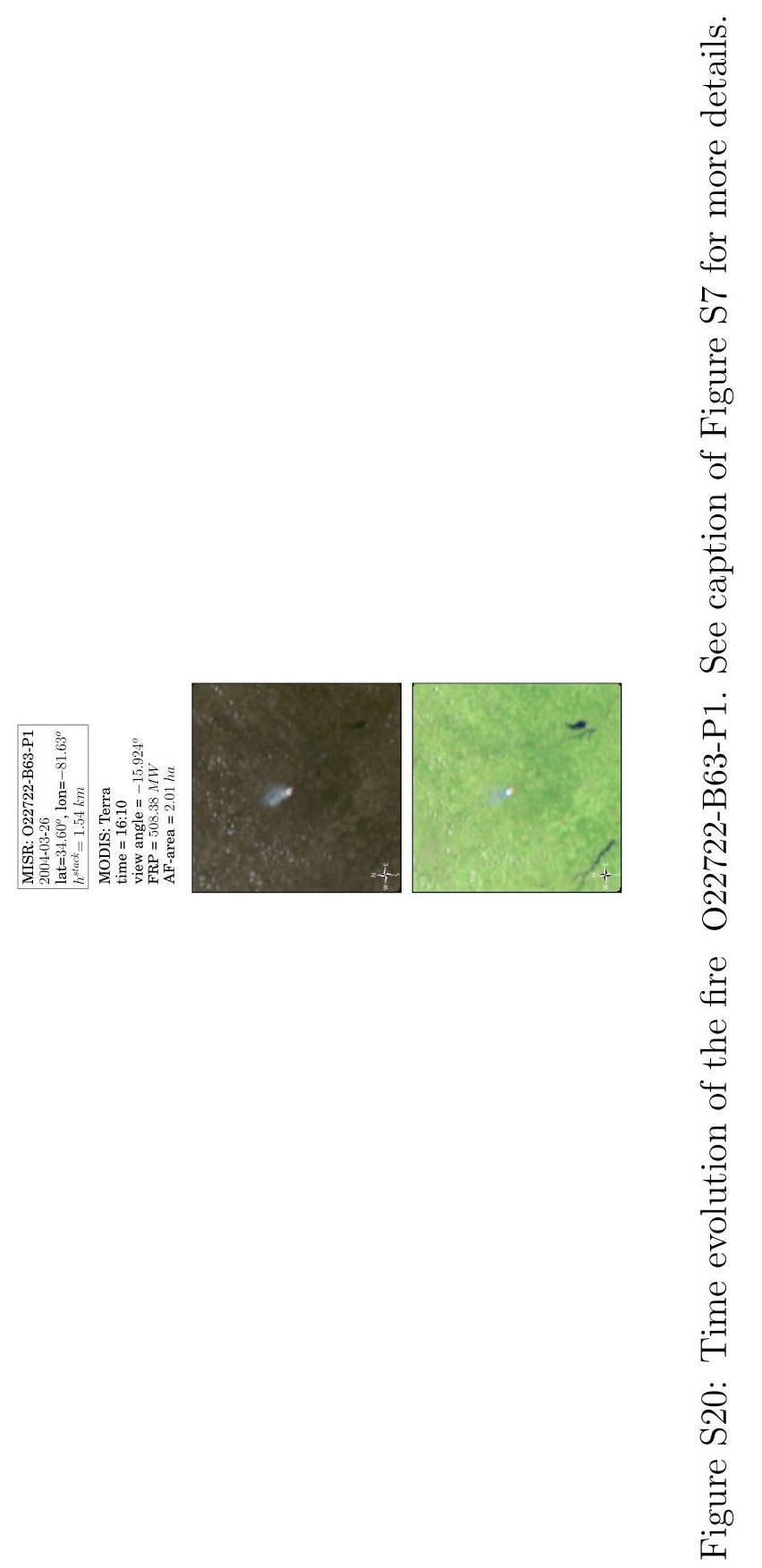




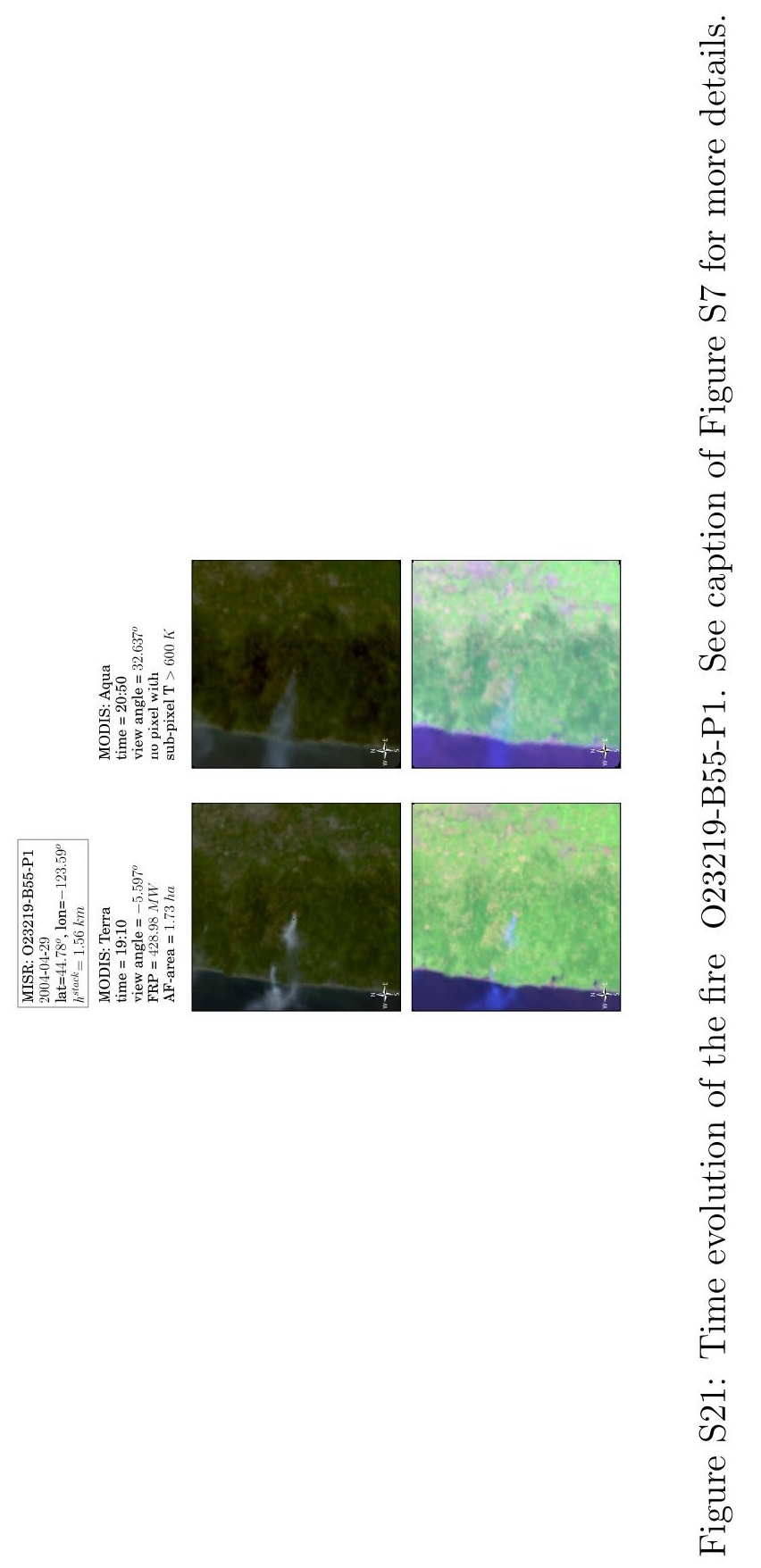




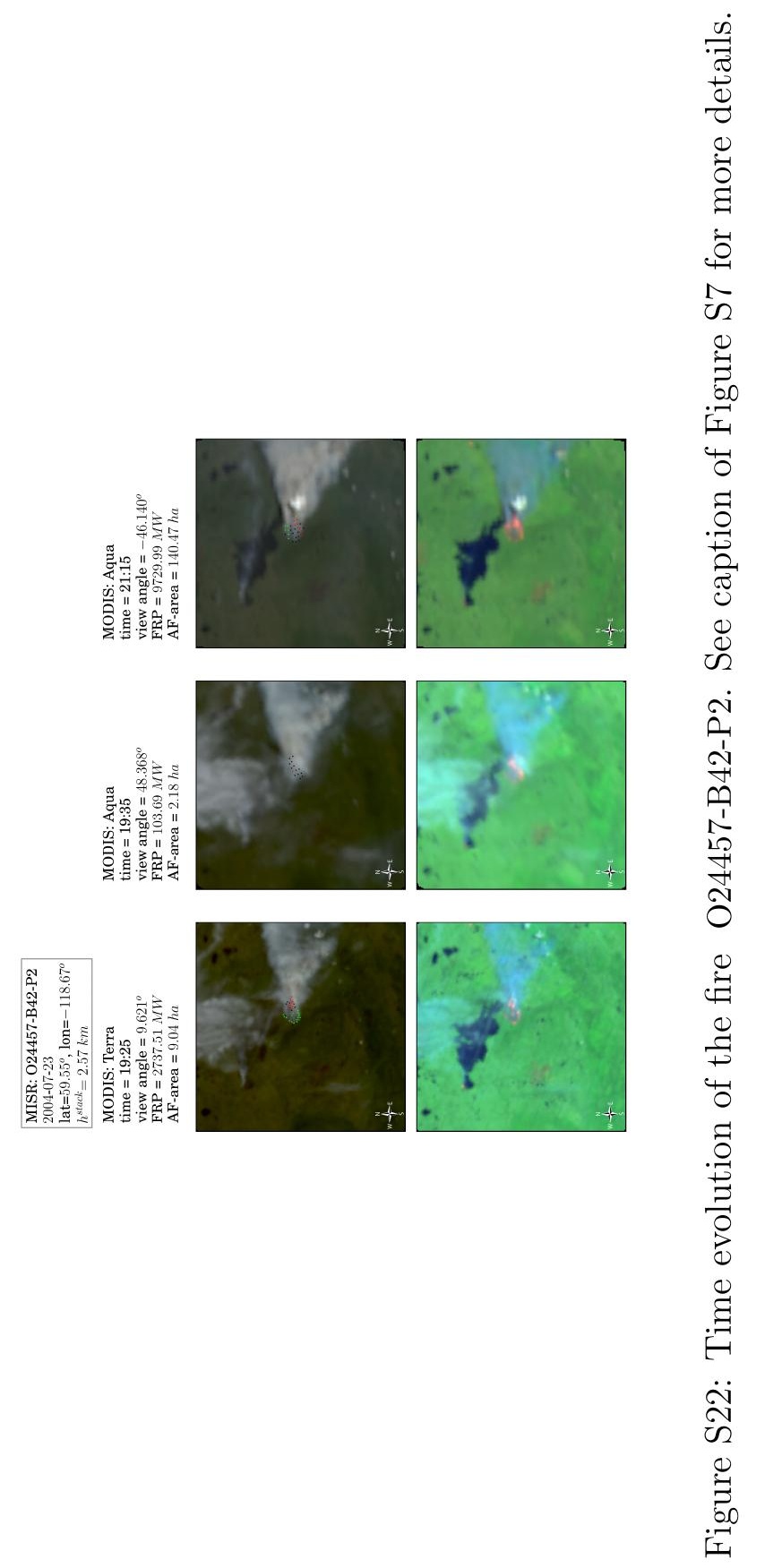




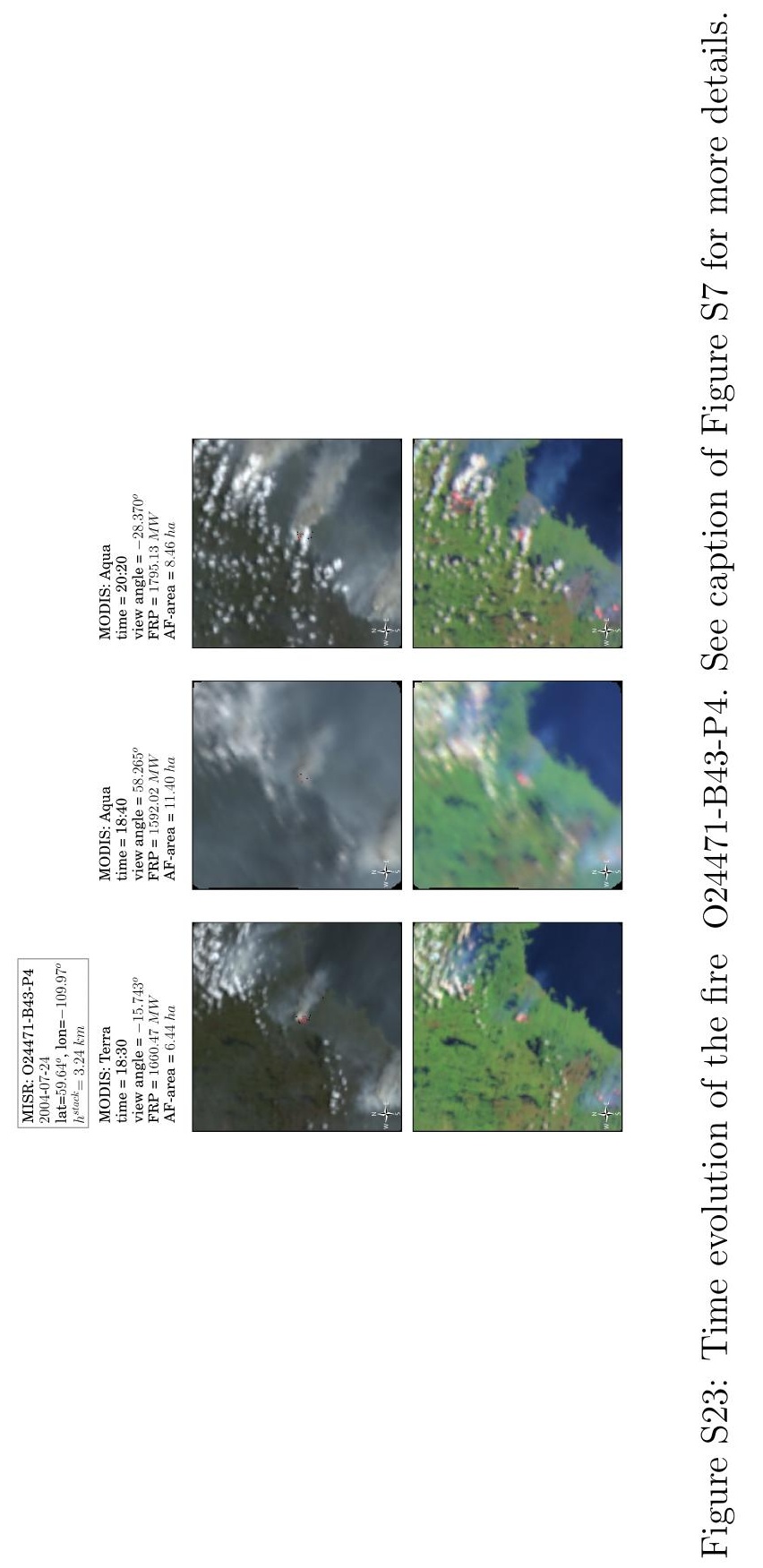




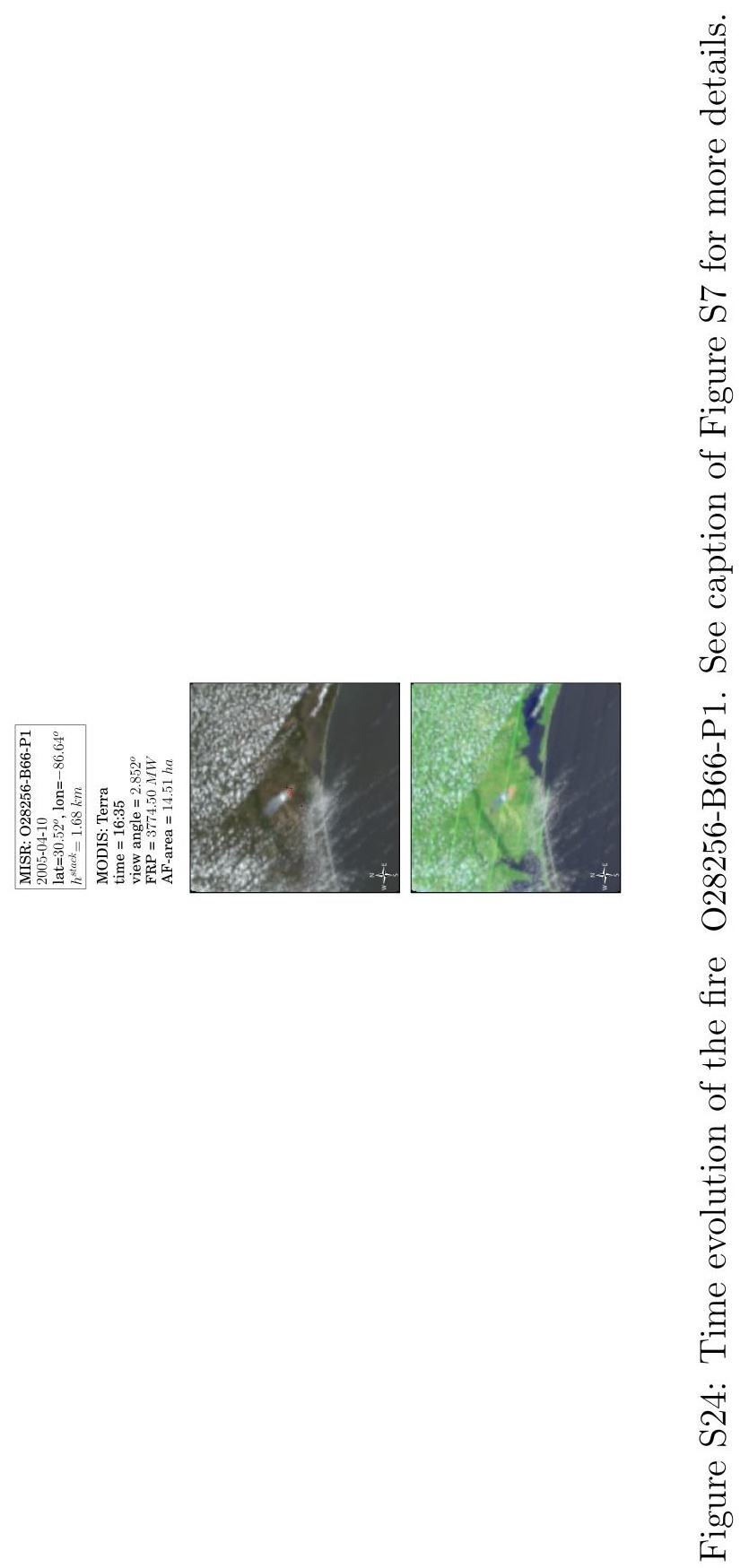




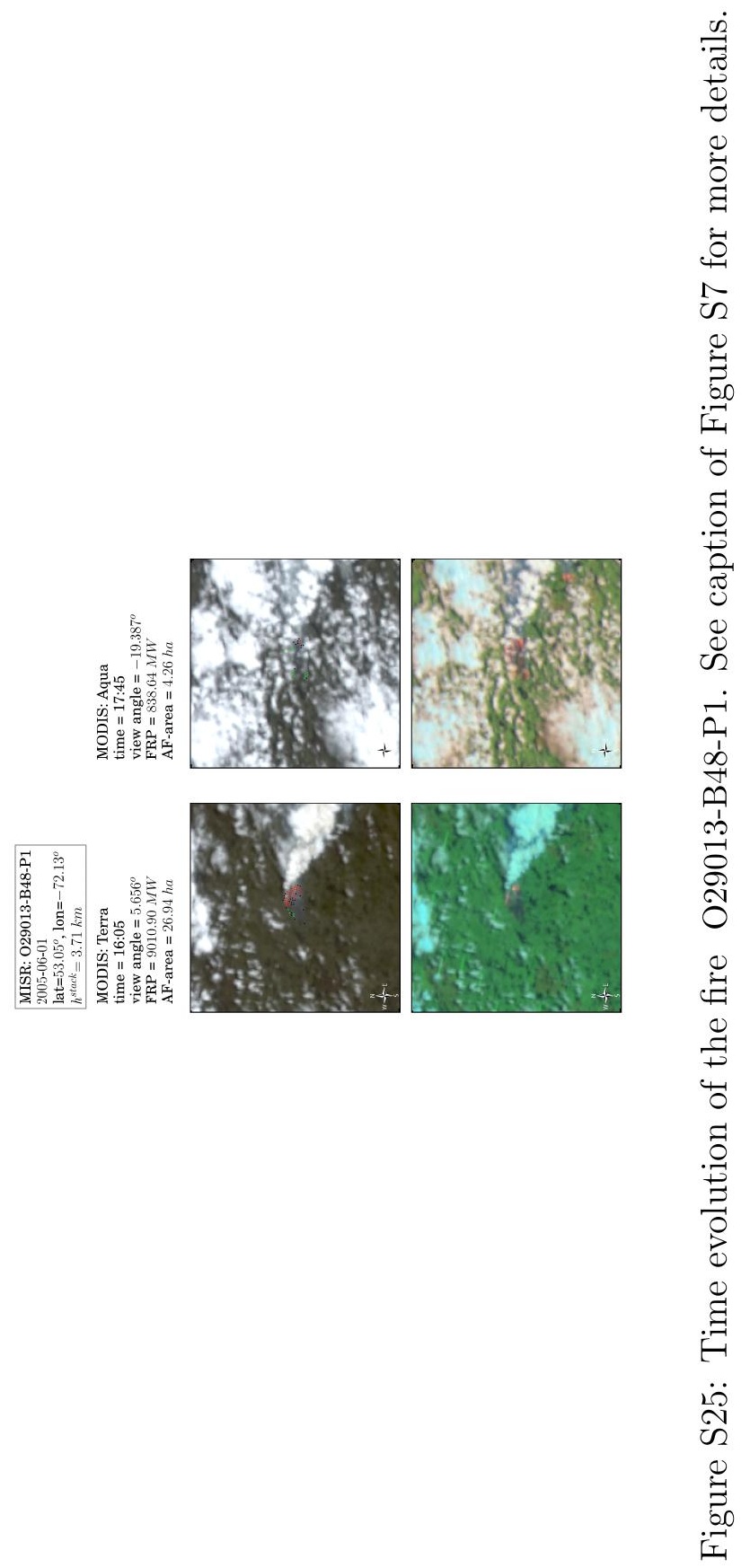




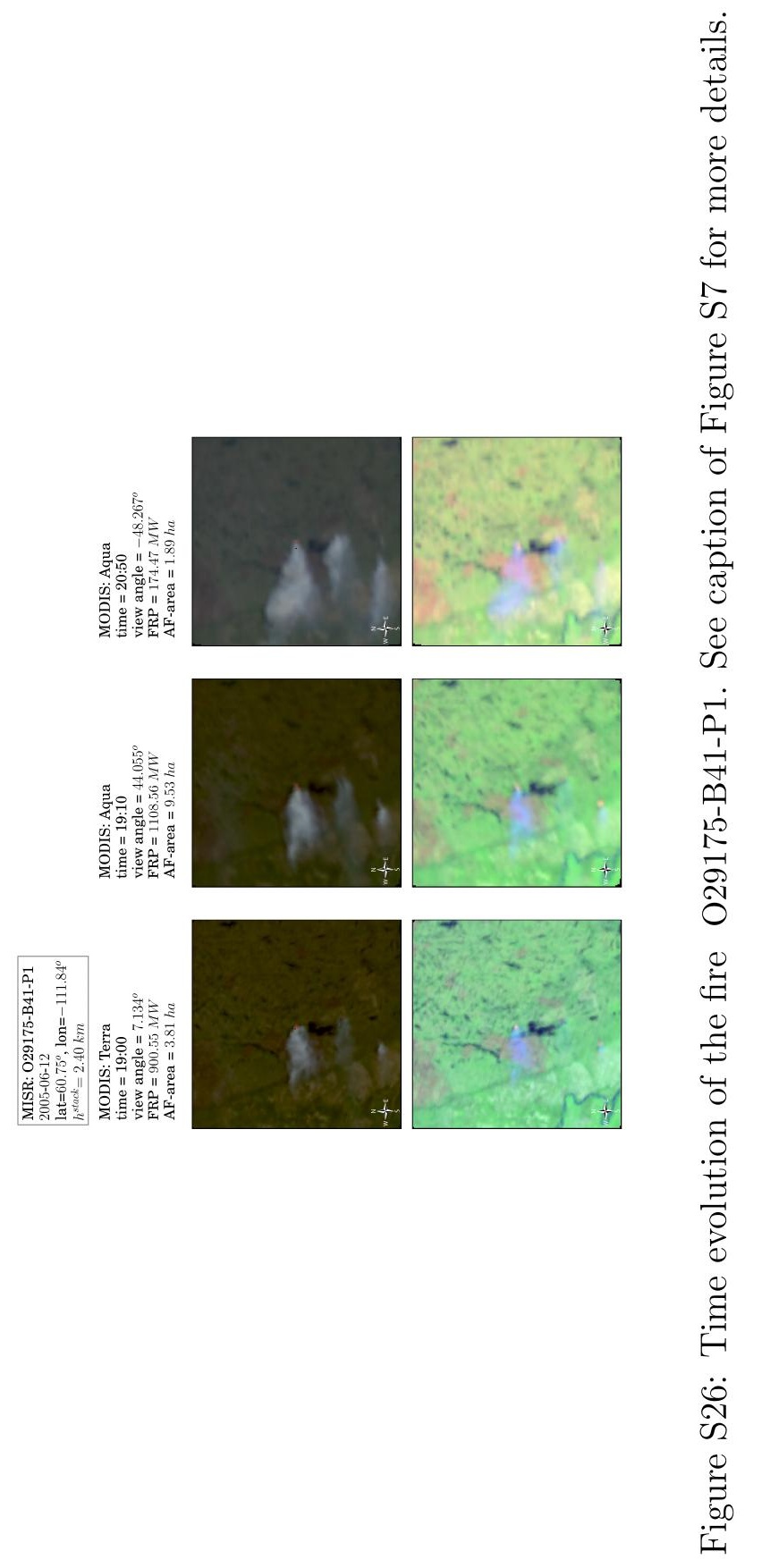




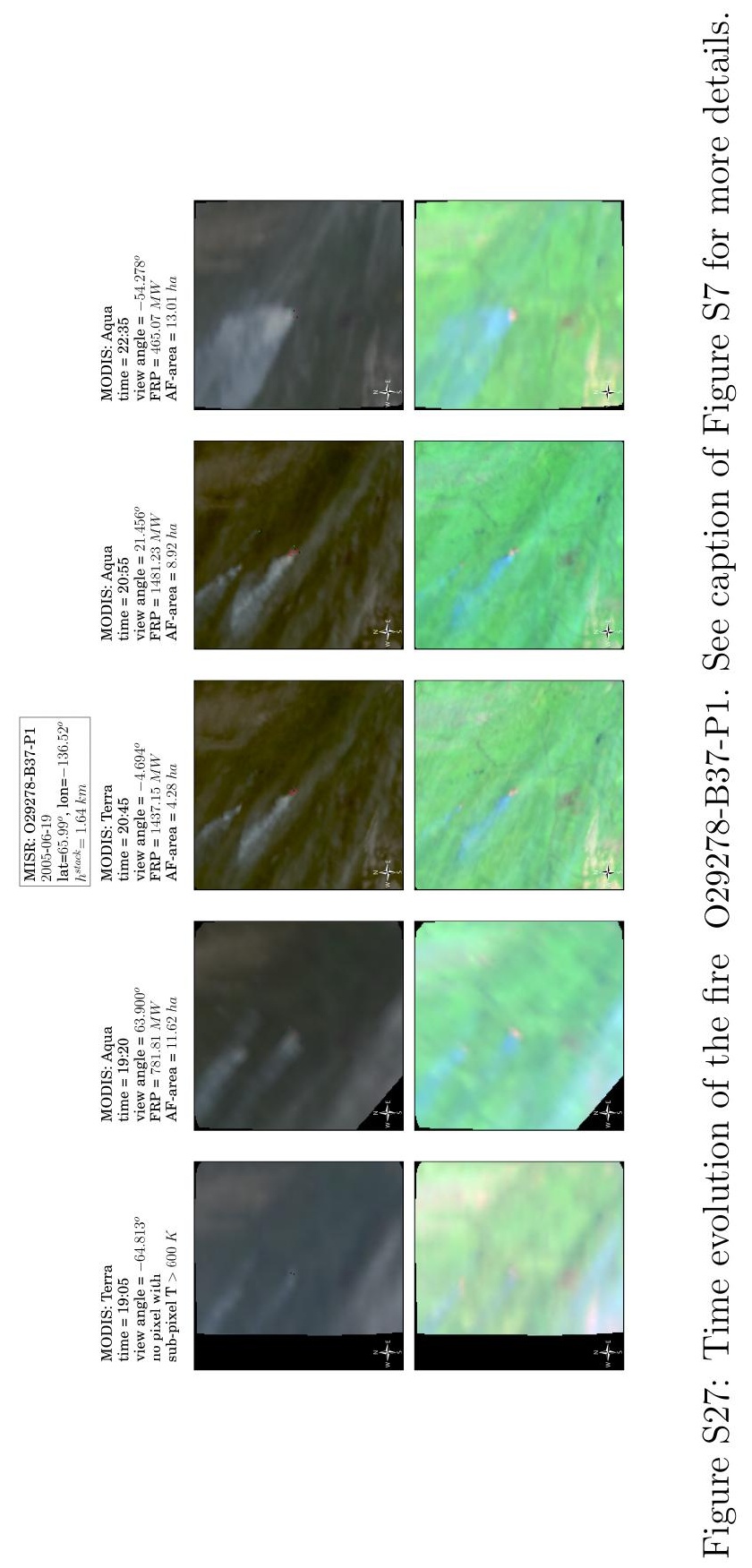




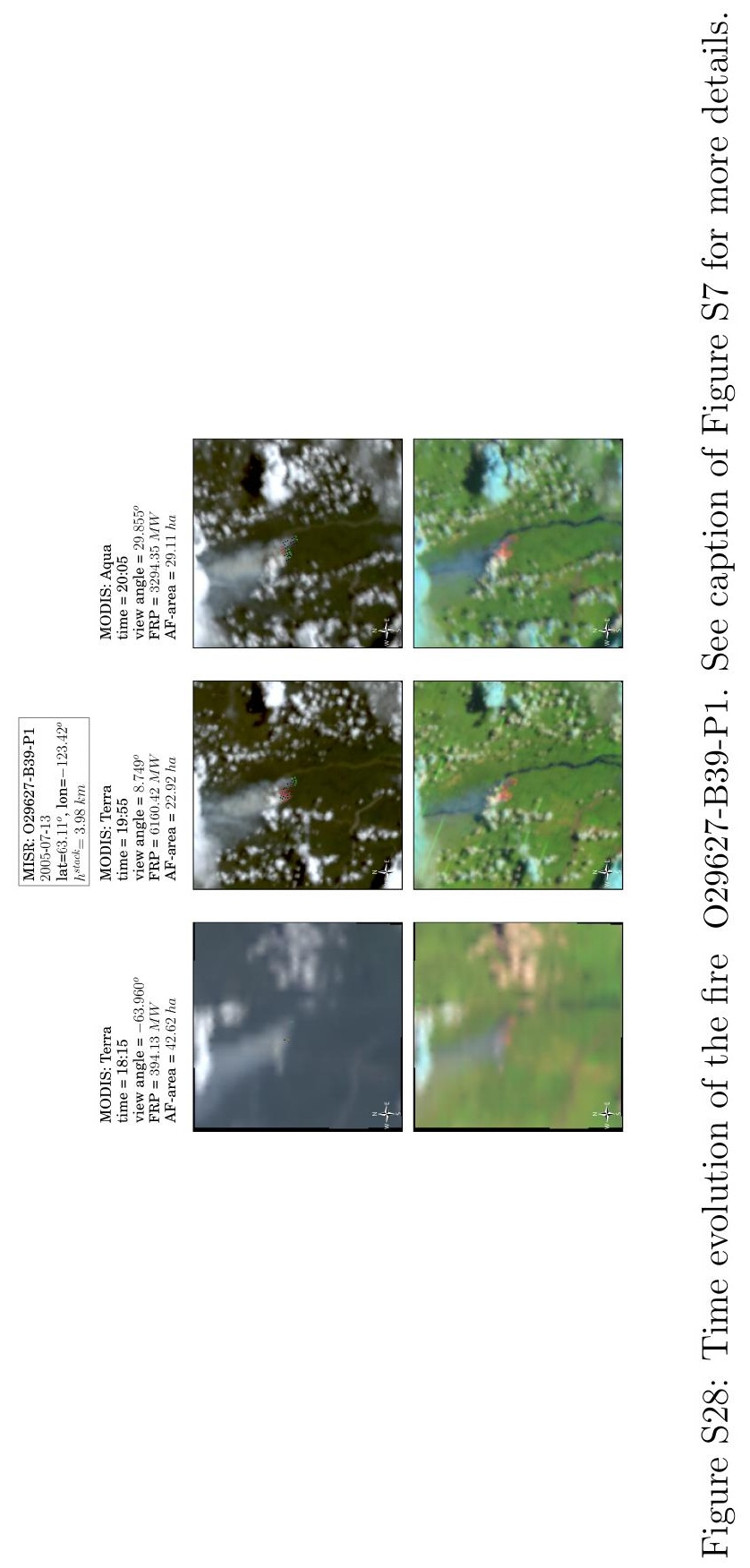




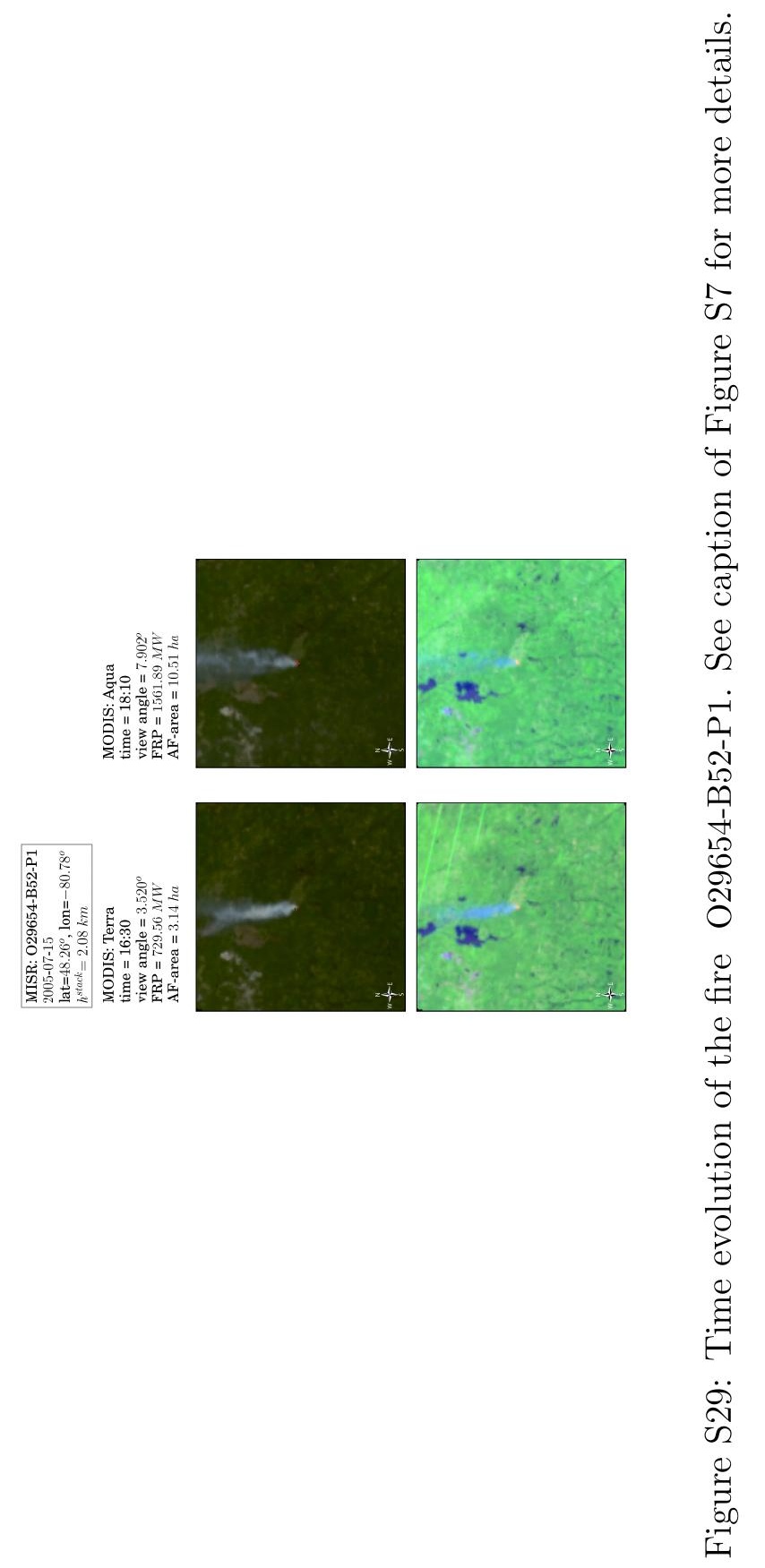




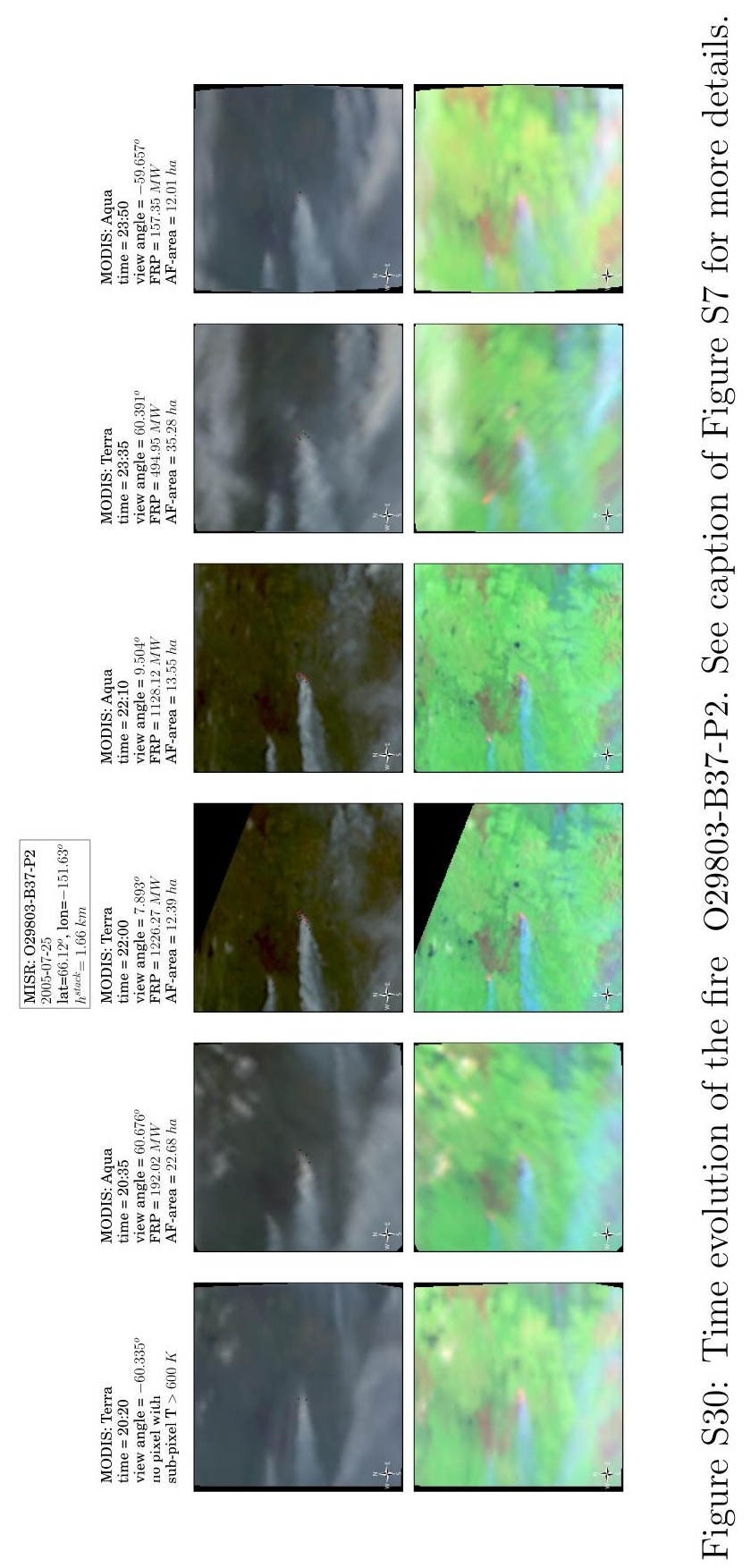




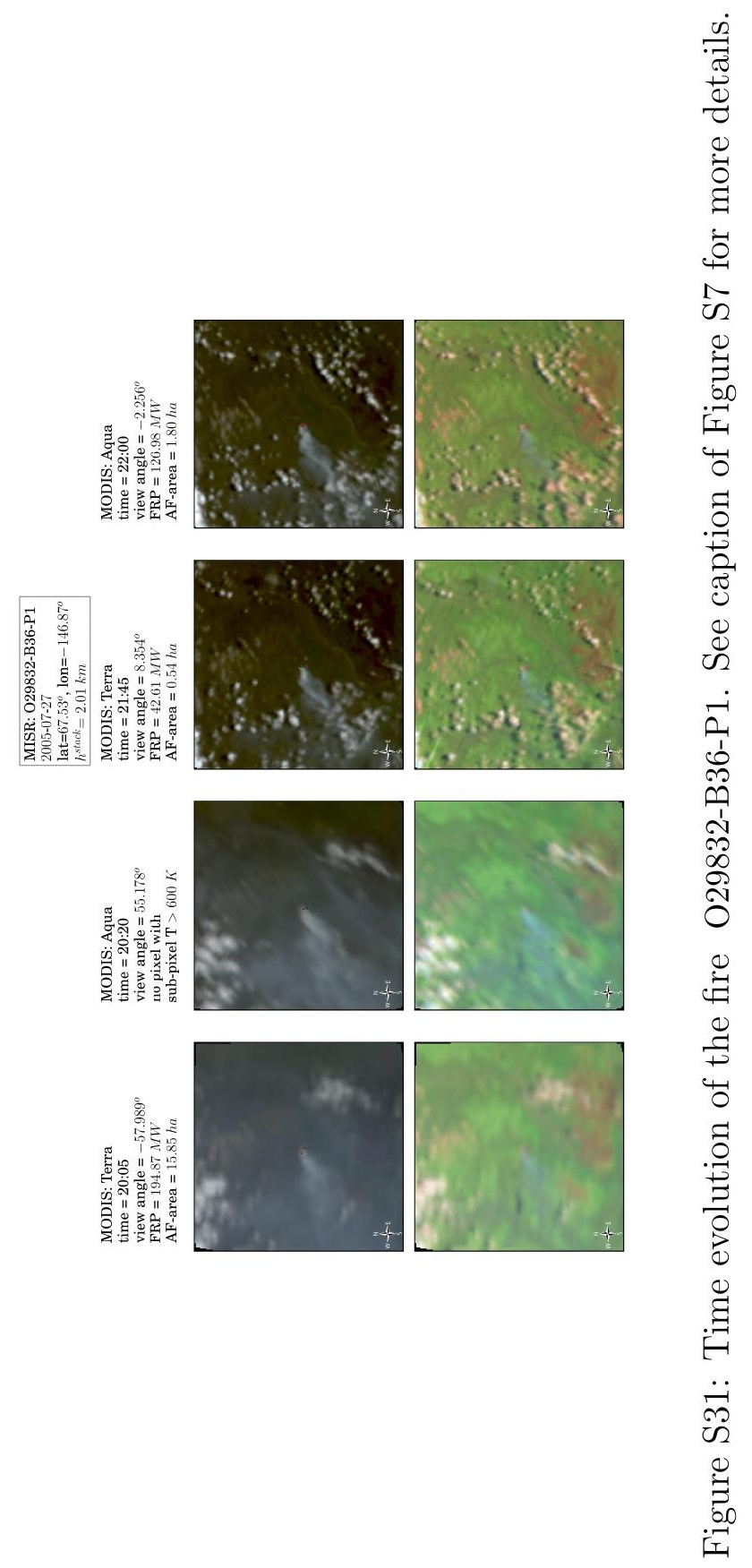




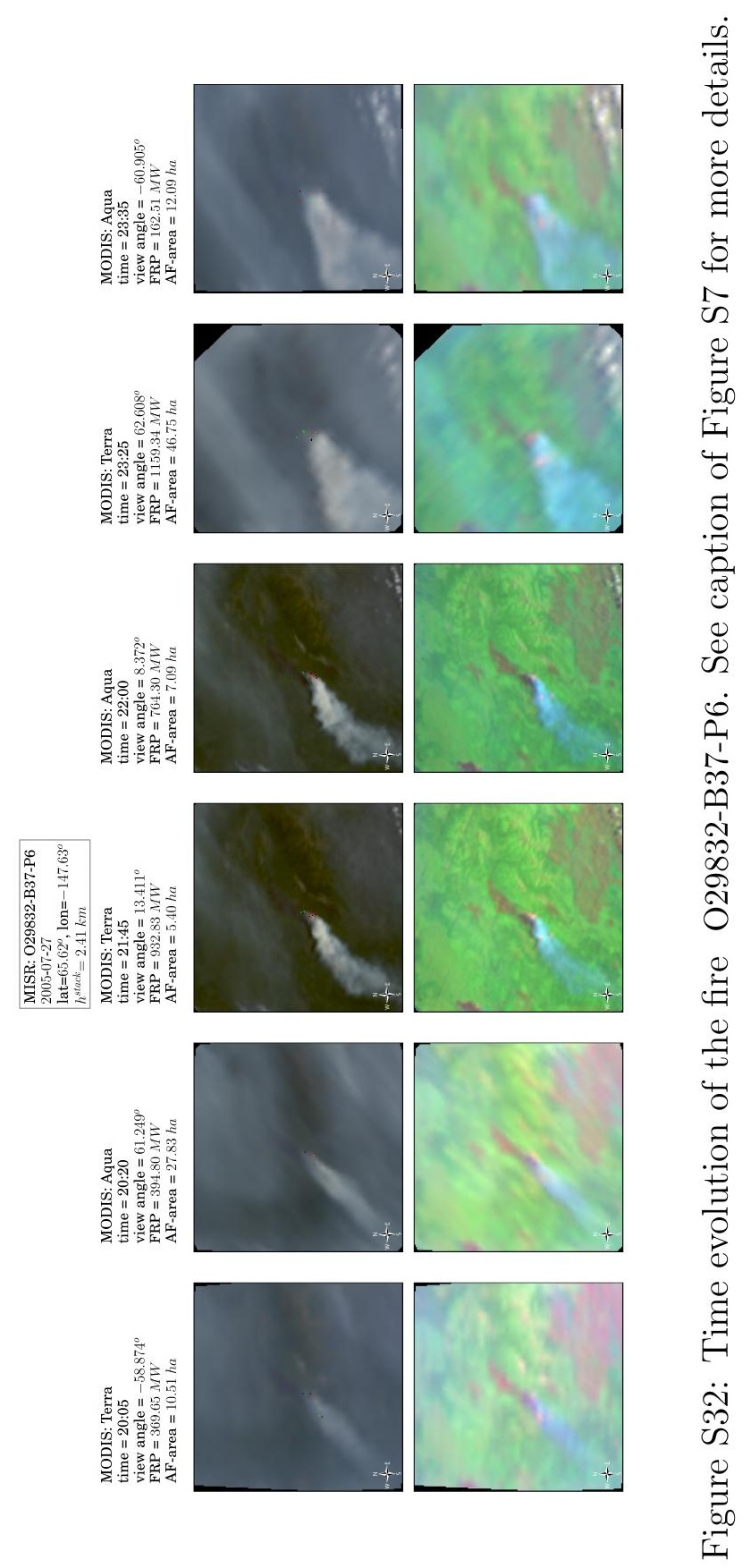




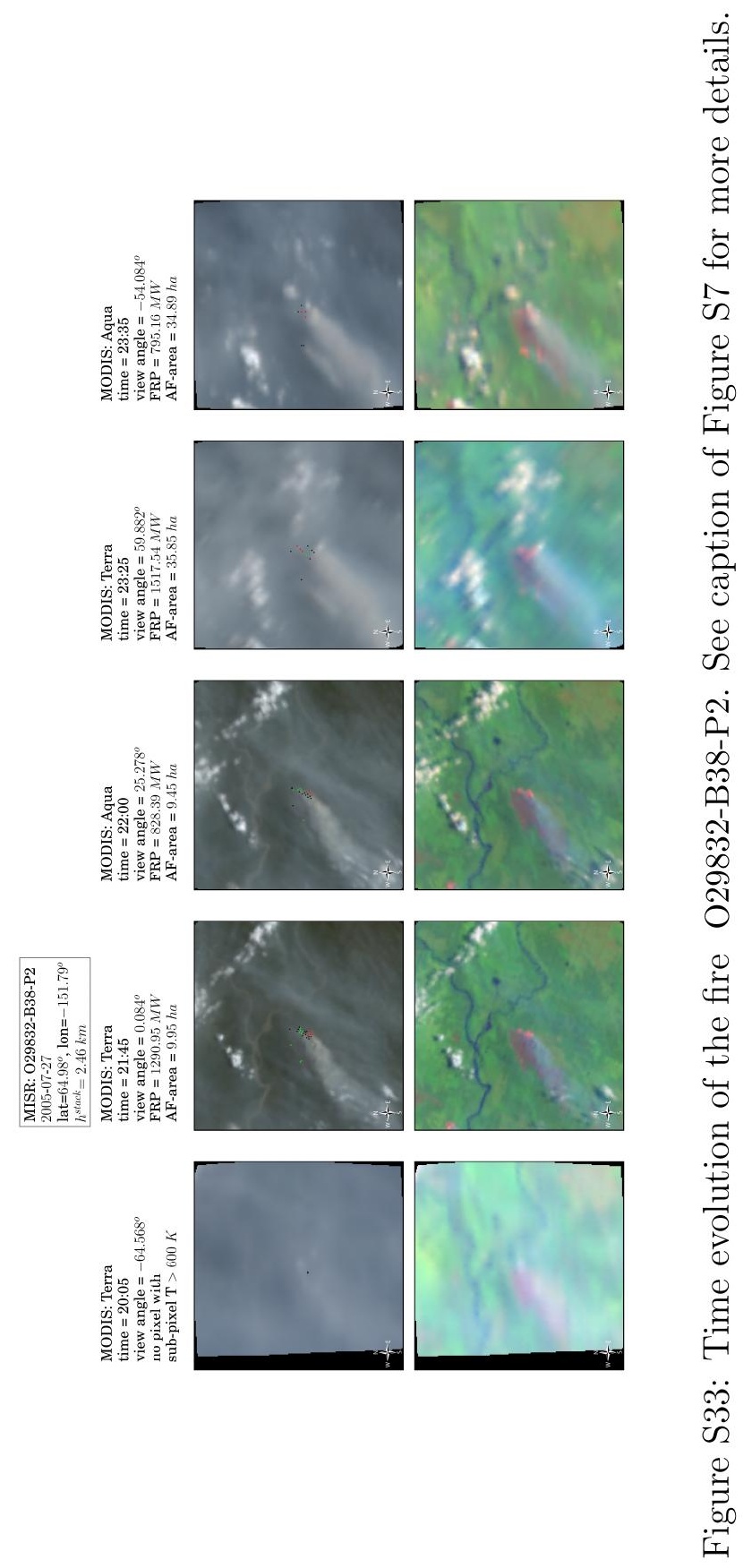




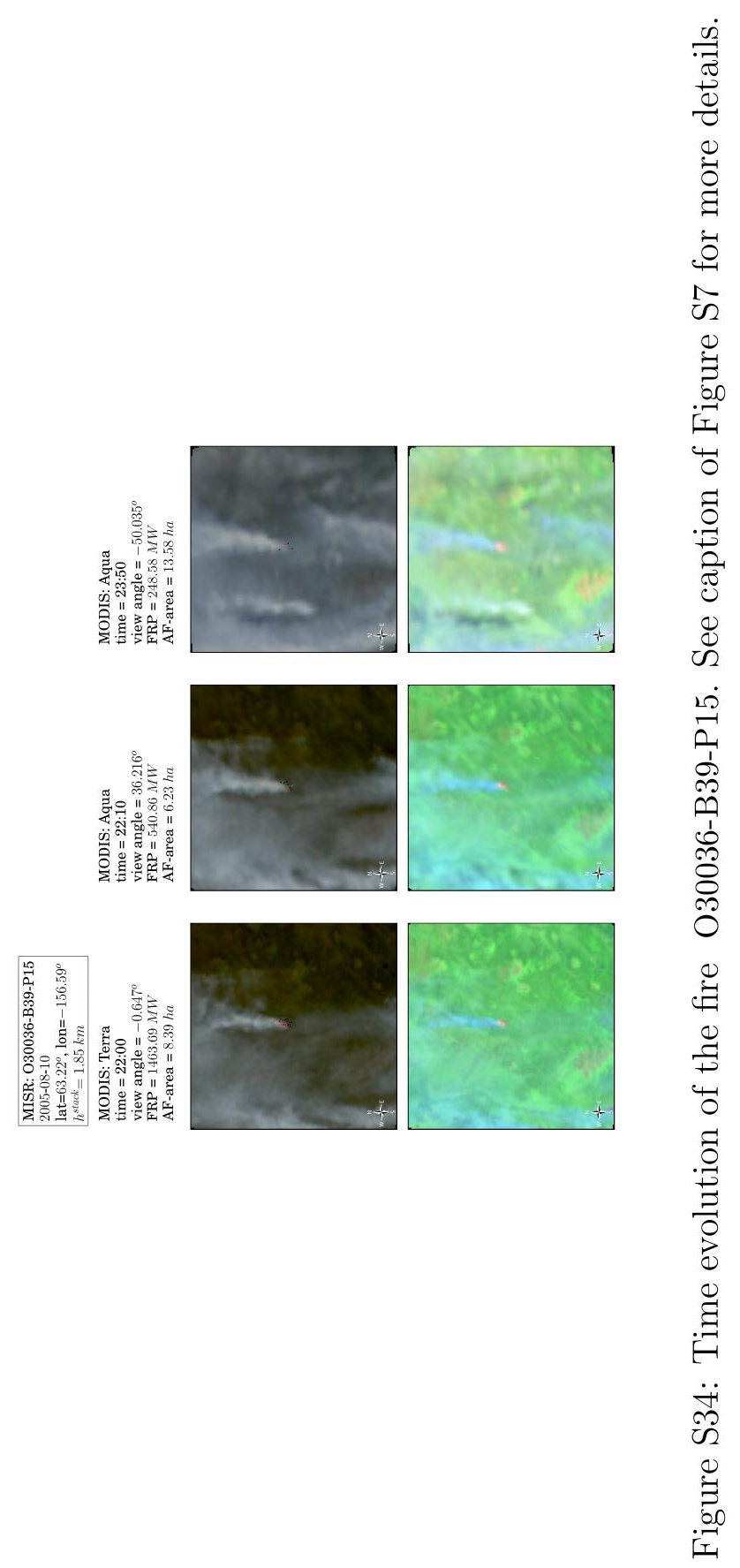




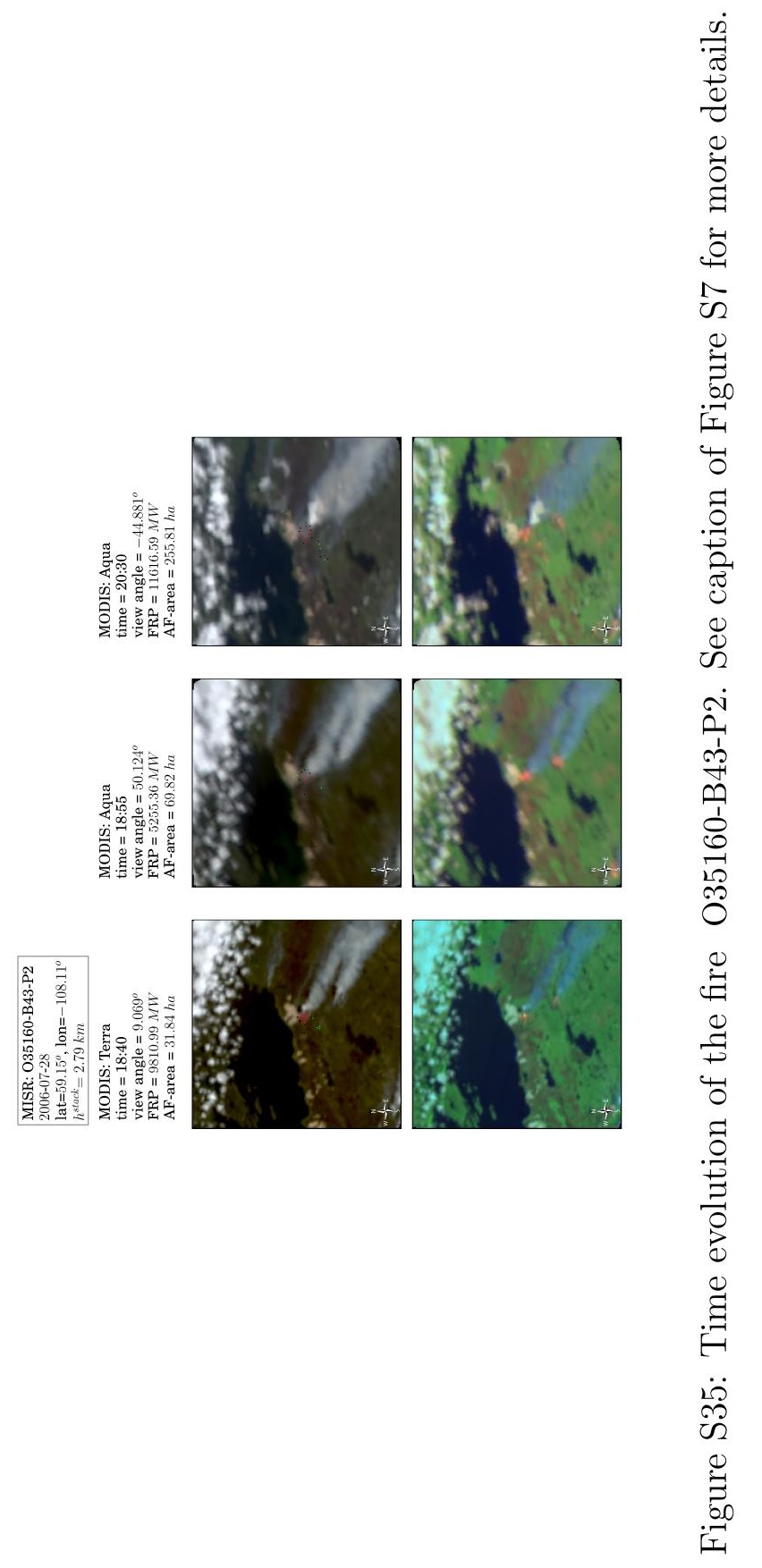




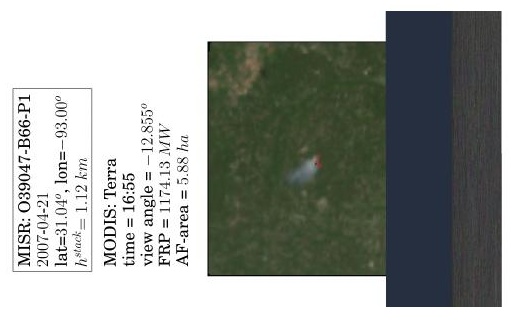

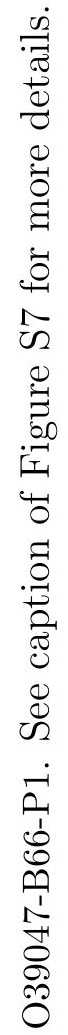

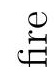

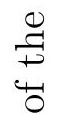

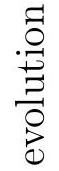

忌

$\ddot{0}$

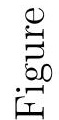




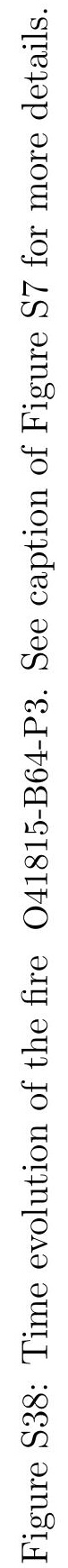




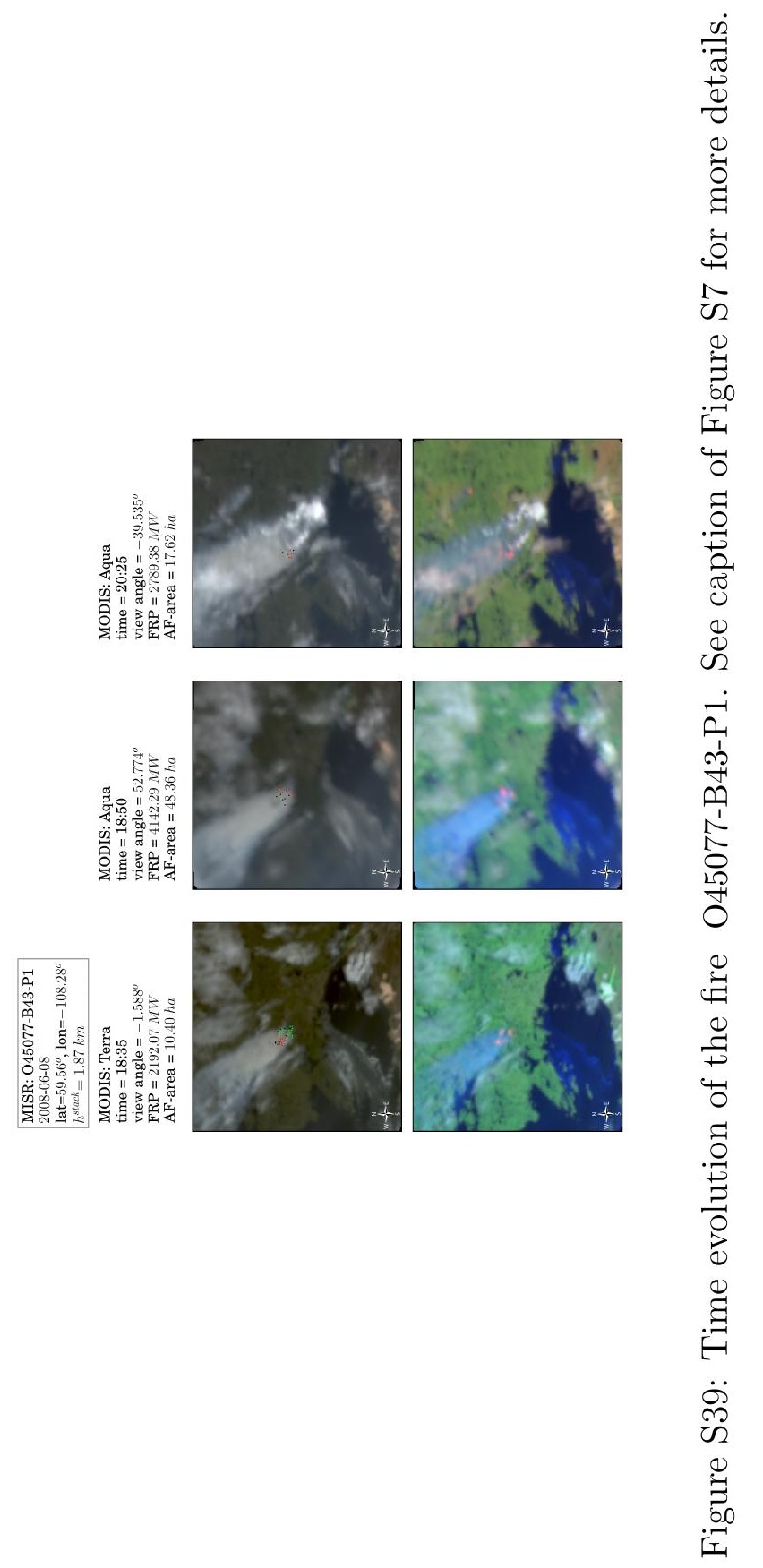




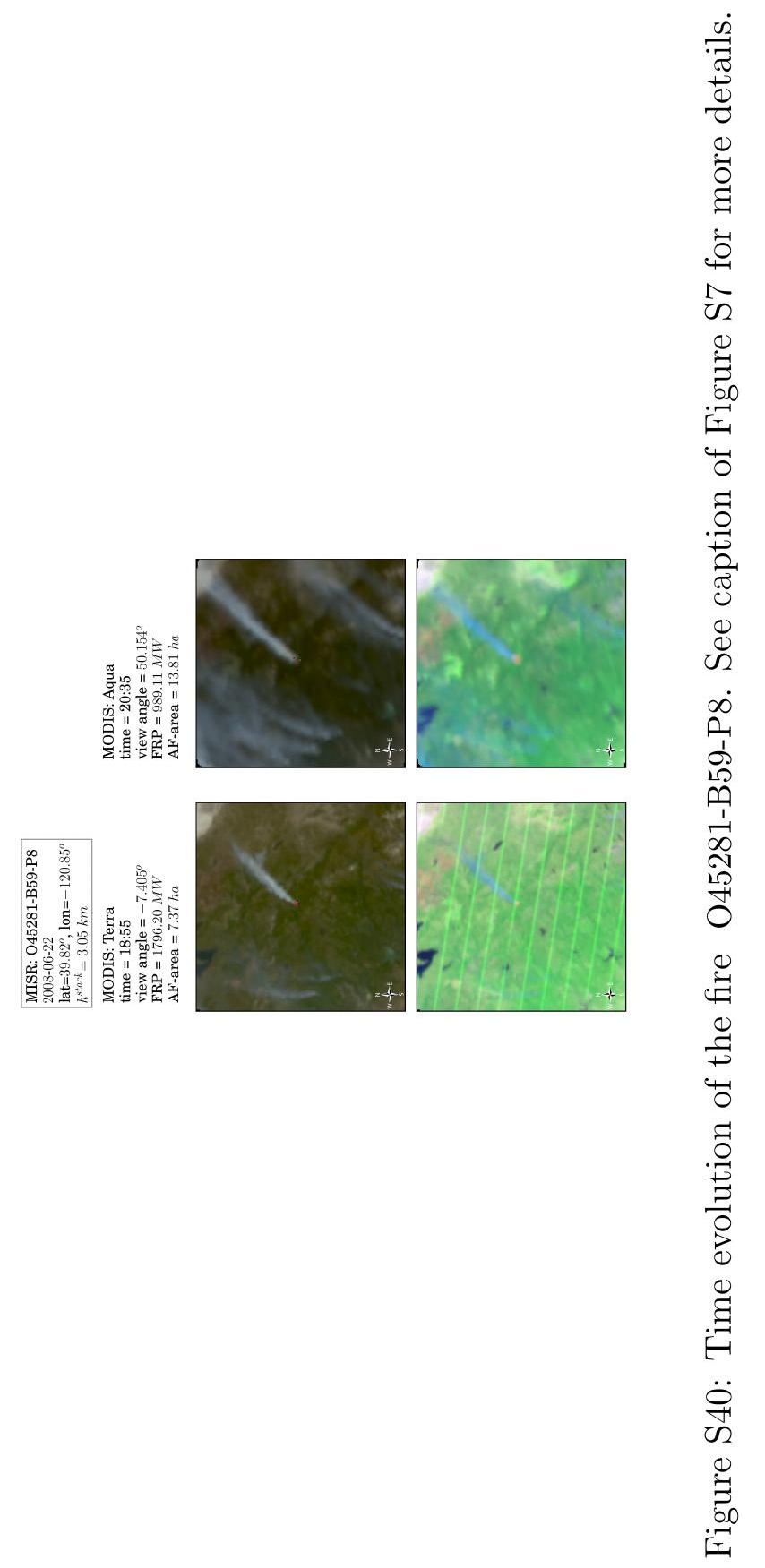




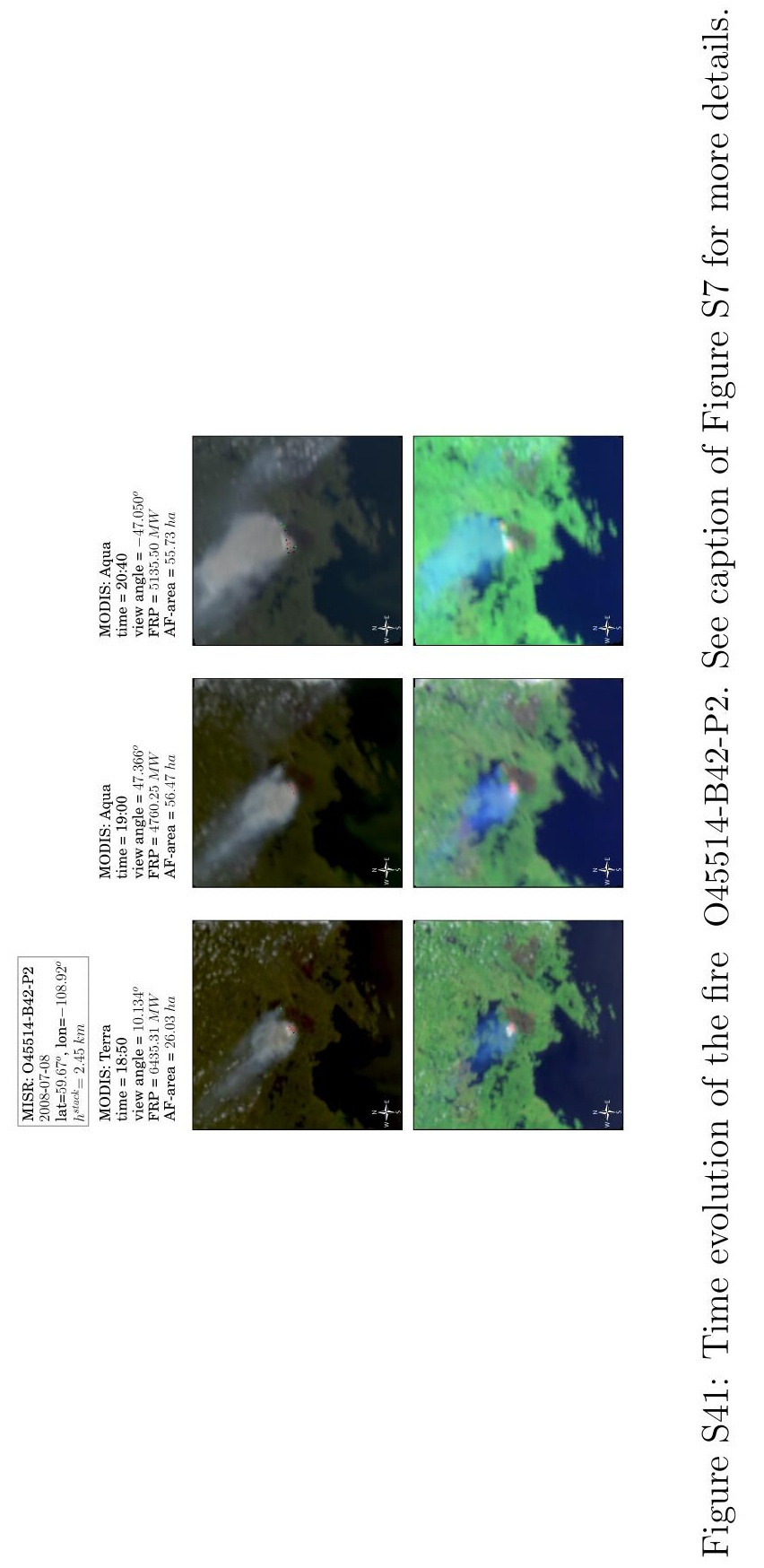




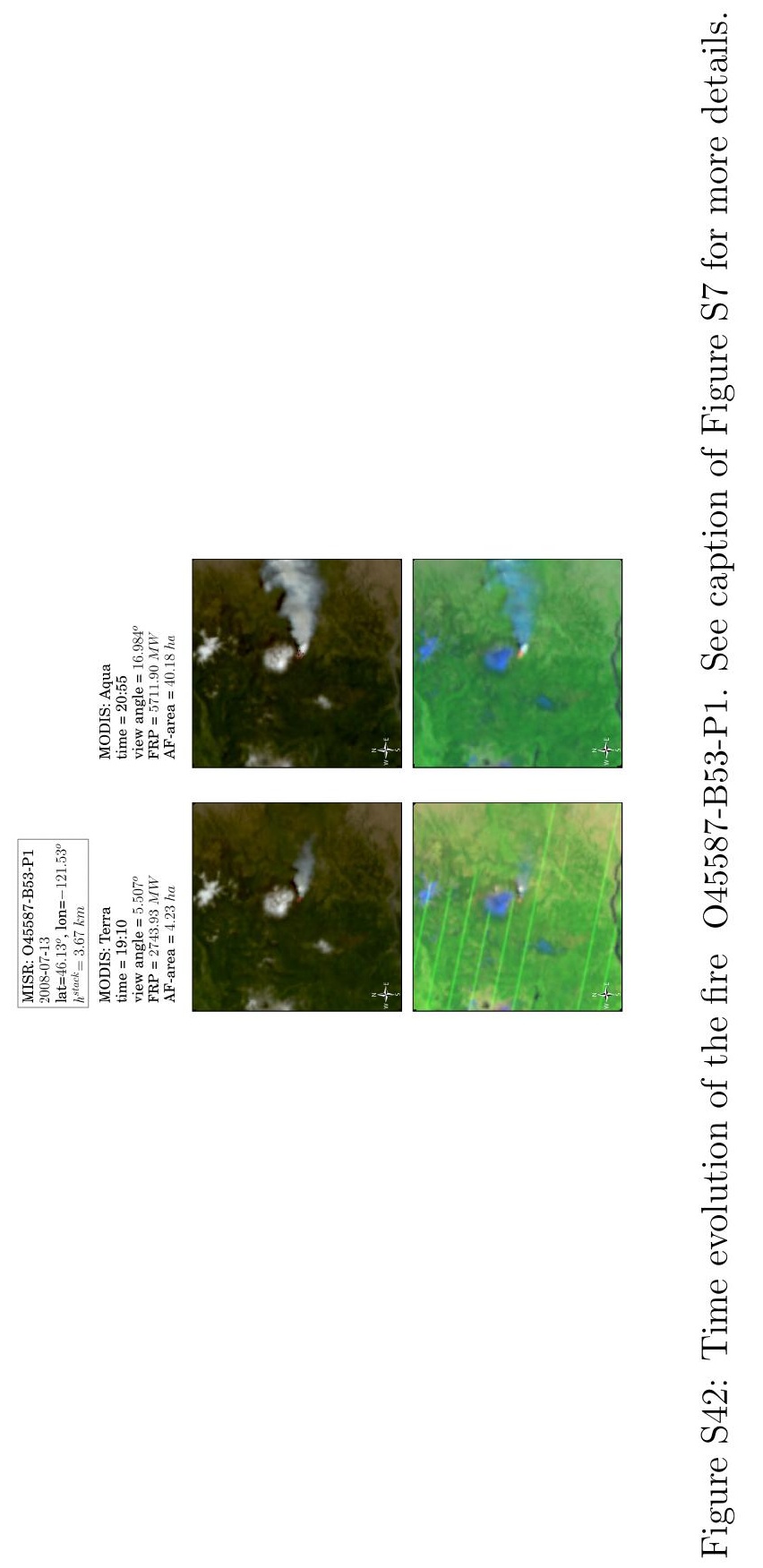




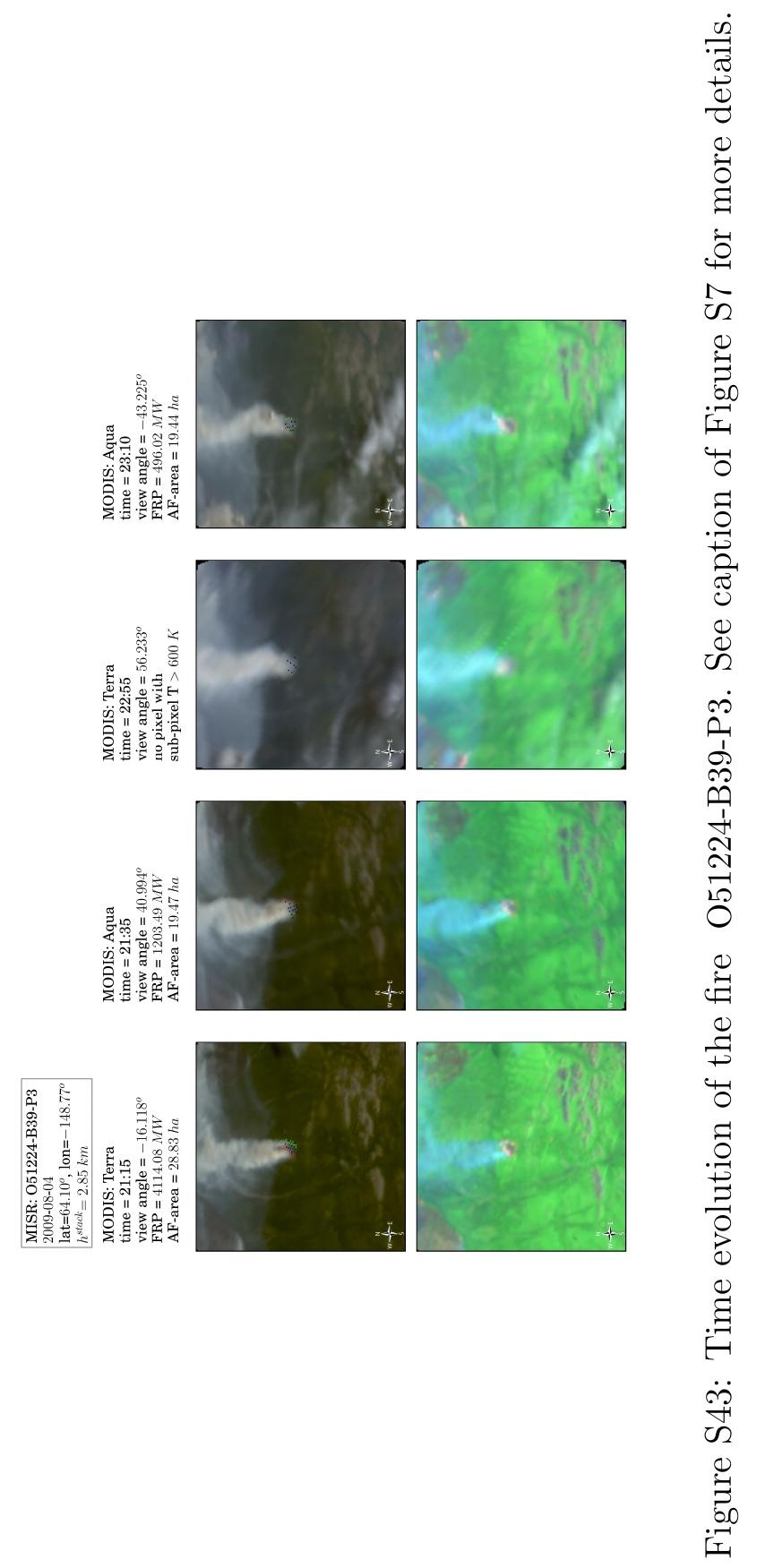




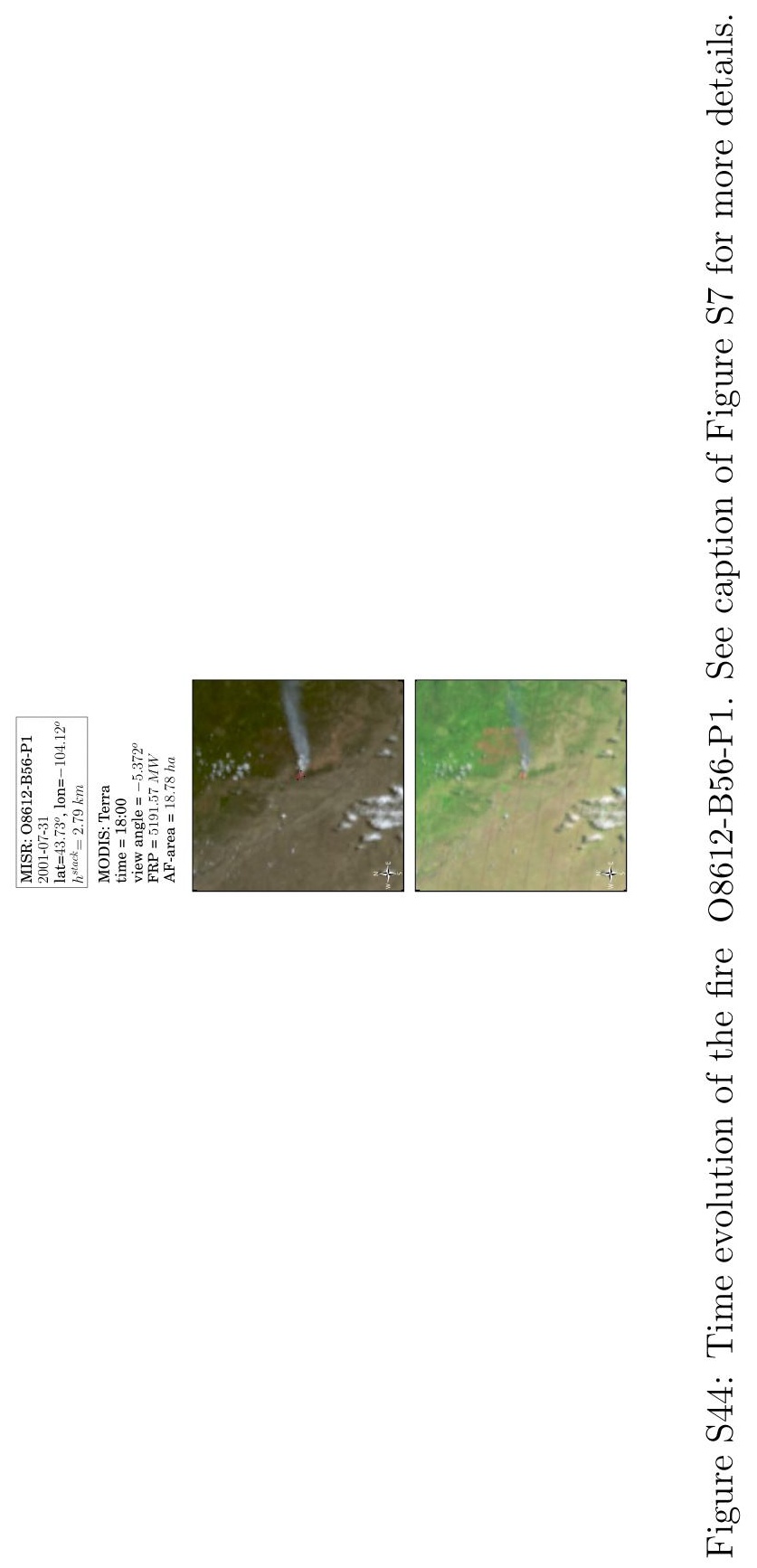




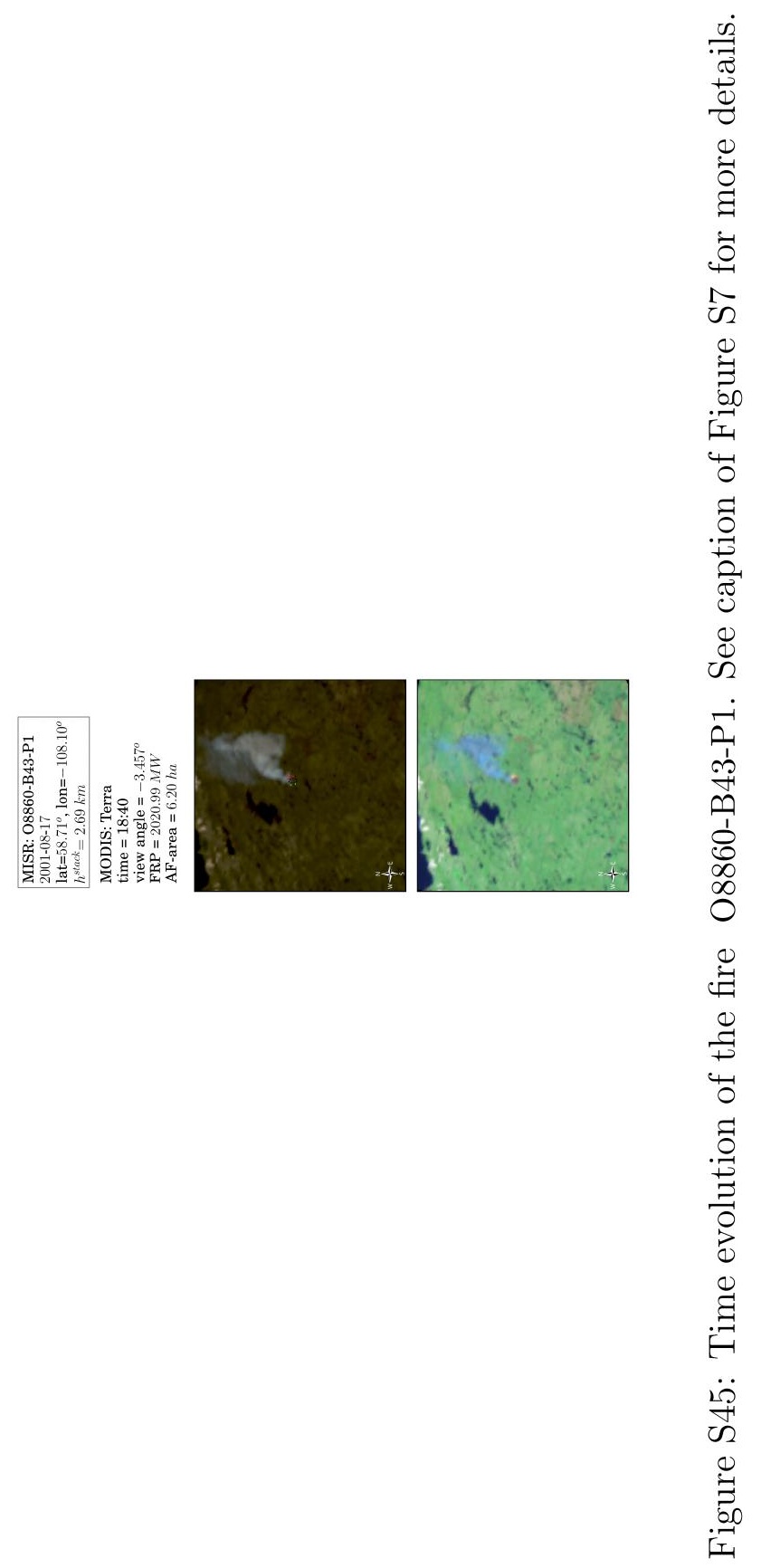




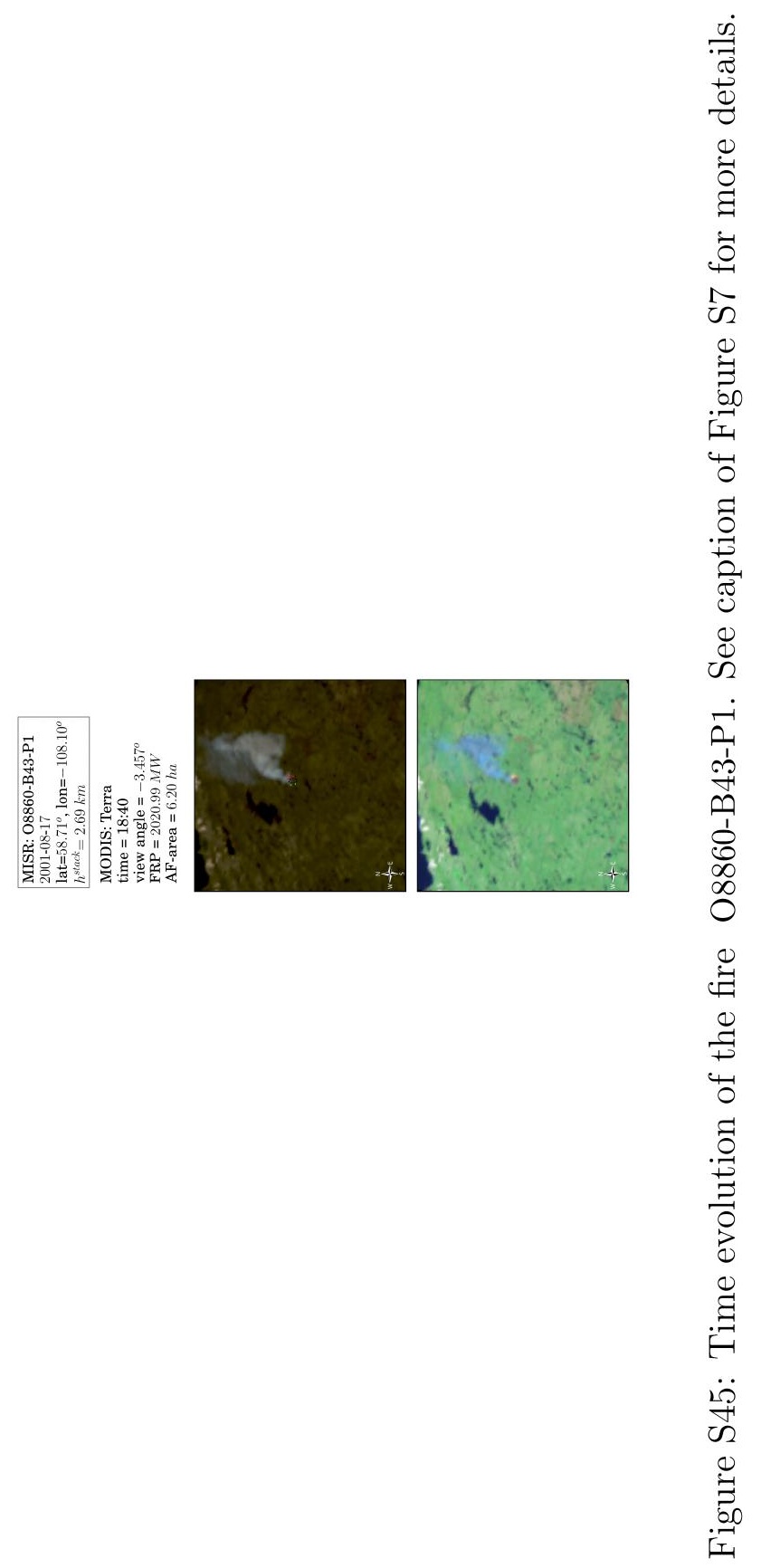

